This manuscript is a preprint and has been submitted for possible publication in Remote Sensing of Environment. This has not been peer reviewed before and is currently undergoing peer review for the first time. Please note that subsequent versions of this manuscript may have slightly different content based on reviewer comments.

However, if accepted, the final version of this manuscript will be available via the 'Peer-reviewed Publication DOI' link on this webpage. Please feel free to reach out to the authors with suggestions/constructive feedback.

\title{
3 A Review of Satellite Remote Sensing Techniques of River Delta Morphology
}

4

5

6

7

8

9

10

11

12

13

14

15

16

17

18

19

20

21

22

23

24

25

26

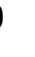

11

2

3

6

8

9

0

1

2

3

4

5

6

\section{Change}

Dinuke Munasinghe ${ }^{1 *}$, Sagy Cohen ${ }^{1}$ and Krishna Gadiraju ${ }^{2}$

${ }^{1}$ Department of Geography, University of Alabama, Tuscaloosa, AL, USA.

${ }^{2}$ Department of Computer Science, North Carolina State University, Raleigh, NC, USA.

*Corresponding Author: dsmunasinghe@crimson.ua.edu

4

15

17


1. Introduction

1.2 The Morphology of a Delta _ 6

1.3 Importance of Delta Morphology Change Studies___ 7

1.4 Satellite Remote Sensing of Deltaic Morphology Dynamics___ 8

1.5 Motivation for this Review __ 9

2. Indicators of Delta Morphology Change___ 10

3. Delta Shoreline Change Detection Techniques ___ 14

3.1 Classification Techniques used in Two-Step Change Detection __ 21

3.1 (A) Pixel-Based Methods _ 21

3.1.1 Manual Digitization _ 21

3.1.2 Density Slicing __ 22

3.1.3 Image Segmentation and Edge Detection _ 23

3.1.4 Band Ratioing _ 24

3.1.5 Unsupervised Classification _ـ 25

3.1.6 Supervised Classification _ 26

3.1.7 Transformation methods_ 27

3.1.8 Artificial Neural Networks (ANN)_ 29

3.1.9 Decision Trees and Random Forest Classifiers __ 31

3.1 .10 Bayesian Networks _ 33

3.1.11 Support Vector Machines __ 35

3.1.12 Object-based Image Analysis (OBIA) _ 36

3.1 (B) Sub-pixel-based methods __ 38

3.1.13 Fuzzy Logic _ 39

3.1.14 Spectral Mixture Analysis___ 40

3.1.15 Sub-Pixel Analysis _ 41

3.1.16 General Concerns about Techniques used in Two-Step Change Detection __ 41

3.2 Classification Techniques used in One-Step Change Detection __ 42

3.2.1 Image Differencing/Layer Arithmetic ___ 42

3.2.2 Change Vector Analysis ___ 43

3.3 Ensemble Classifications _ 44

4. Other Delta Morphology Change Indicators __ 46

4.1 Meander Belts _ 47

4.2 Crevasse Splays, Channel Avulsions and Distributary Networks __ 48 
$63 \quad 4.3$ Barrier Islands, Beach Spits, and Mouth Bars

64 5. Synthesis and Applications ___ 51

$65 \quad 5.1 \quad$ Machine Learning ___ 51

$66 \quad 5.2 \quad$ Radar Imagery __ 54

67 6. Intercomparison of Delta Morphology Feature Extraction Techniques __ 55

68 7. Future Directions __ 60

69 Direction 1: Utilization of higher resolution imagery and developing better sub-pixel data

70 mining techniques___ 60

71 Direction 2: Use of automated pattern recognition techniques, universal applicability and

72 algorithm transferability across platforms___ 63

73 Direction 3: Improvement of Ancillary data___ 64

74 Direction 4: A Global Information System of deltaic data __ 65

75 8. Conclusions _ 66

769 9. References __ 67

77

78

79

80

81

82

83

84

85

86

87

88

89

90

91

92

93

94 
River deltas are important coastal depositional systems that are home to almost half a billion

97 people worldwide. Understanding morphology changes in deltas is important in identifying vulnerabilities to natural disasters and improving sustainable planning and management. Satellite remote sensing has shown to be a useful technology for analyzing these morphology changes owing largely to its capability to provide spatially continues observations. In this paper, we critically review the literature about satellite remote sensing techniques that were used to study 102 delta morphology changes.

We identify and categorize the techniques reported in the literature into 3 major classes: 1) Onestep change detection, 2) Two-step change detection, and 3) Ensemble Classifications. In total we offer a review of 18 techniques within these categories. Example studies, the strengths and 106 caveats in relation to the deltaic environment are discussed for each technique. Our synthesis of 107 the literature reveals that sub-pixel-based algorithms perform better than pixel-based ones.

108 Machine learning techniques rank second to sub-pixel techniques although an ensemble of 109 techniques can be used just as effectively to achieve high feature detection accuracies.

110 We evaluate the 7 most commonly used techniques in literature (Conventional Techniques: (1)

111 Modified Normalized Difference Water Index (MNDWI), 2) Normalized Difference Water 112 Index (NDWI), 3) PCA analysis, 4) Unsupervised Classification, and 5) Supervised

113 Classification)]. Machine Learning techniques: 6) Random Forest Classifier, and 7) Support

114 Vector Machine) on a sample of global deltas, for delta morphological feature extraction

115 performance. Findings show the Unsupervised Classification significantly outperforms the others 116 and is recommended as a first order feature extraction technique in previously unknown, or, data 117 sparse deltaic territories. 
118 We propose four pathways for future advancement in satellite remote sensing of delta

119 morphology: 1) utilizing new high-resolution imagery and development of more efficient data

120 mining techniques, 2) moving toward universal applicability of algorithms and their

121 transferability across satellite platforms, 3) improvement of the availability and use of ancillary

122 data in image processing algorithms, and 4) development of a global-scale repository of deltaic

123 data for the sharing of scientific knowledge across regions and disciplines. 


\section{Introduction}

\subsection{The River Delta and its Importance}

A river delta is defined as a discrete shoreline protuberance formed from deposition of sediment where rivers enter oceans, semi enclosed seas (coastal embayments), lakes or lagoons (adapted from Elliott, 1986). Deltaic regions are home to more than 490 million people, including several megacities (Syvitski \& Saito, 2007). These hubs act as major centers for agriculture (Syvitski \& Saito, 2007), fisheries (Woodroffe et al., 2006), and hydrocarbon production (Syvitski et al., 2009), offering employment opportunities for millions, and consequently making deltaic regions some of the most economically productive systems in the world (Woodroffe et al., 2006). The ecological significance of river deltas lies in the fact that they act as coastal storm surge protectors, biodiversity hotspots, provide habitats for many animal and plant species, provide pathways for migratory species and carry with them a cultural heritage which is a high revenue generation mechanism for local communities (Hutchings \& Campbell, 2005; Lentz et al., 2016).

\subsection{The Morphology of a Delta}

Morphology, in the simplest of terms, is the configuration or form of a river delta in its natural environment. The morphology of modern deltaic systems (so named because their formation/progradation began during the late Holocene period, subsequent to the last glacial period; Allison et al., 2003) is controlled by the complex interaction between boundary conditions and forcing factors (Coleman and Wright, 1975; Orton and Reading, 1993; Postma, 1995; Syvitski and Saito, 2007). These forcing factors include (1) supply of bedload and suspended sediment load: reflecting drainage basin characteristics, water discharge, sediment

yield and grain size; (2) deposition/accommodation space: reflecting sea-level fluctuations, 
159 offshore bathymetry, tectonics, subsidence, compaction, and isostasy; (3) coastal energy:

160 reflecting waves and tides, longshore and cross-shelf transport; and (4) density differences

161 between effluent and receiving waters defining the dynamics of sediment plumes. The complex

162 interaction between these factors result in the formation of different features (e.g. main delta

163 landmass governed by the delta shoreline, sandbars/barrier islands, beach spits). These features,

164 which are component environments of the delta, collectively describe the morphology of the 165 delta, reflect the status quo of the river delta, and can be used to monitor changes to the delta 166 through time.

\section{$167 \quad 1.3 \quad$ Importance of Delta Morphology Change Studies}

168 Most modern deltas serve societal needs such as protecting residents, resources, and

169 infrastructure, or preserving biodiversity and ecosystem services. Human settlements and

170 infrastructure in low-lying deltaic regions are particularly vulnerable to floods induced by intense

171 precipitation and storm surges (Motsholapheko et al., 2011; Sanchez-Arcilla et al., 2012). Floods

172 disrupt cultivation in delta plains, livestock farming, destroy property leading to displacement of

173 households, interrupt water reticulation systems, and curtail transport systems, thereby impacting

174 a country's economic growth significantly (Bendsen and Meyer, 2002; Motsholapheko et al.,

175 2011). Therefore, knowledge on morphology change is important to plan engineering works such

176 as identification of vulnerable areas, installation of coastal defense structures (e.g. breakwaters,

177 weirs), confinement or widening of river channels, dredging, sand extraction, dam construction,

178 development of setback planning and hazard zoning.

179 In addition to mitigate against flooding, delta morphology change information is also important 180 for constructing engineering structures for transport, land reclamation and urbanization, erosion- 
181 accretion studies, regional sediment budgets, restoration activities for extensively altered deltas, 182 and for conceptual or predictive modeling of coastal morphodynamics (Sherman and Bauer,

183 1993, Al Bakri, 1996, Zuzek et al., 2003; see Maiti and Bhattacharya (2009); Masria et al., 2015;

184 Le et al., 2007). Therefore, understanding and predicting these morphology change dynamics is 185 of utmost importance for sustainable planning of deltaic communities.

\subsection{Satellite Remote Sensing of Deltaic Morphology Dynamics}

187 During the past four decades satellite remote sensing technologies have emerged as a viable 188 alternative to in-situ observations of river deltas and associated deltaplain morphology changes

189 (Figure 1: evolution of the Yellow river delta during the satellite era). This is mainly attributed to 190 their availability over large geographical regions, the effectiveness of the delta-change mapping 191 techniques, the temporal coverage of a given location, and the relatively low cost for large aerial 192 extents (Mathers and Zalasiewicz, 1999; Zhao et al., 2008; Zhang et al., 2015; Munasinghe et 193 al., 2018). Although delta morphology mapping based on ground surveys and aerial observations 194 (e.g. aerial photography, drone footage) is a viable and useful option, such methods are time195 consuming, expensive and, in most cases, cannot provide data on time scales commensurate with 196 delta morphology change. Remotely sensed data can be seamlessly used as a stand-alone tool, or 197 in tandem with complementary numerical modeling and statistical efforts. 

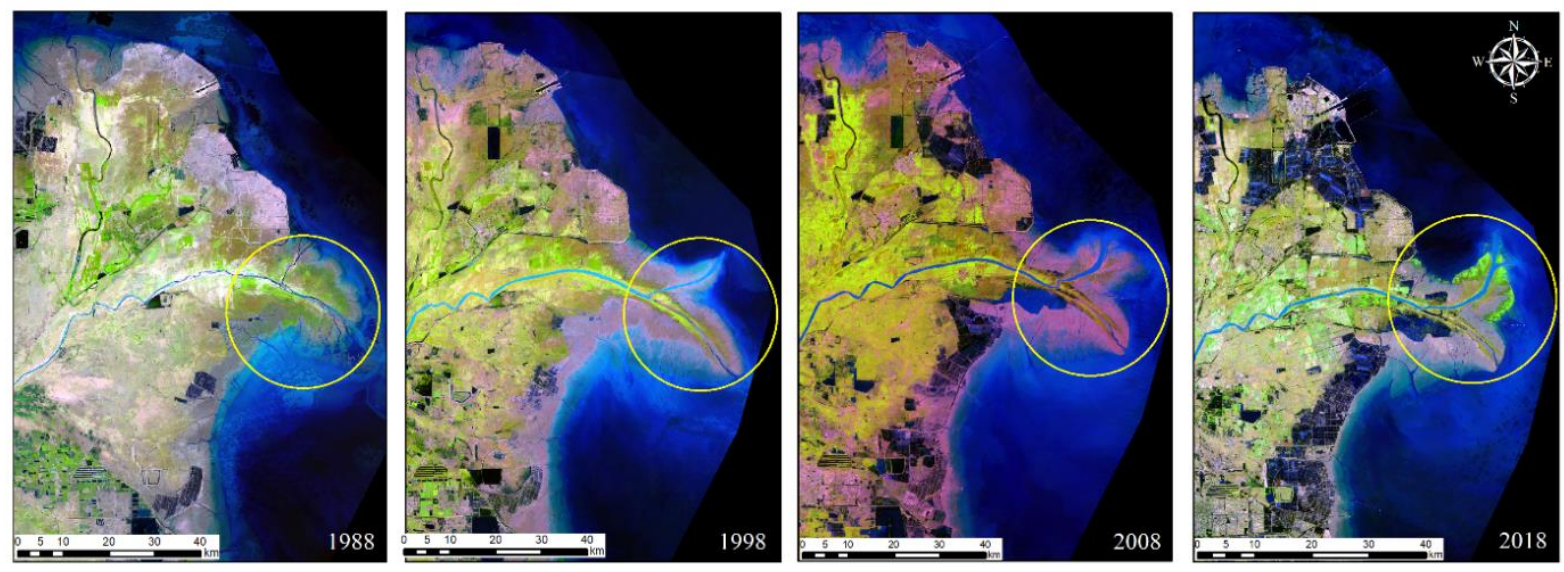

Figure 1: Landsat satellite imagery showing the evolution of the Yellow River Delta, China from

1988 to 2018. The circled area shows the downward development of the Qingshuigou Lobe, and the more prominent upward development of the Qing8 Lobe of the delta.

\subsection{Motivation for this Review}

The impetus for this review comes from the non-availability of a single robust document in the literature which portrays past and current research efforts in identifying river delta morphology changes using satellite remote sensing techniques. The need for such a summation stems from several reasons. Morphology detection techniques that work well for one particular river delta might not be ideal for another: This could be due to complications of geometries of river deltas

207 (e.g. influenced by islands, sandbars), sediment plumes transported by rivers (gradational deposition at the river mouth) making the identification of the delta boundaries difficult, geographical location of river delta (governs the type and density of vegetation that grows at the land-sea margin), and tidal forces (determines formation of islands close to the main delta body

211 due to breakage) which all act in varying degrees in determining the performance accuracy of

212 algorithms. This has led to morphology detection algorithms to mostly be location specific. A

213 summation of knowledge as such also aids in morphology detection algorithm selection and

214 application to lesser studied deltaic systems globally, done informatively. The transfer of 
215 knowledge from prior use cases could be done optimistically (by relative comparison of similar

216 delta forms and geographical regions) and with caution (prior understanding of limitations of

217 detection algorithms). Thus, for current research frontiers in deltaic research to expand, a need

218 arises for a comprehensive, organized summary of historical and emerging techniques of delta

219 change mapping of key deltaic environments.

220 We also perform a comparison of remote sensing techniques on an array of delta types (river-,

221 tide-, wave-dominated) from a global sample of deltas to understand the performance of

222 techniques under varying fluvial and marine conditions. Elucidating which technique(s) work

223 best in delta morphological feature extraction would allow us to infer why particular techniques

224 underperform in different regions of the world. This will also highlight some of the inherent

225 problems of particular techniques and will offer a pathway for improving existing algorithms and

226 development of new ones to monitor river delta morphological change.

227 This document reviews the content of 146 articles/book chapters which used remote sensing

228 technologies to detect deltaic features and their changes, and a further 38 articles/book chapters

229 to gather supplementary information on river delta research and technological advances in

230 computational algorithm development. Every effort has been taken to cover the breadth of

231 remote sensing techniques that were used in delta morphology research from 1980 until present

232 day.

233 2. Indicators of Delta Morphology Change

234 A river delta is a collection of different component environments (as described in section 1.2).

235 Changes to these components result in the changes in geometries, sediment facies and

236 depositional architecture of the delta. Thus, these components can be used as 'indicators' to 
237 assess changes to the morphology and can be quantitatively used to derive delta evolution. For

238 example, a decrease in sediment fluxes to the delta can move it from a condition of active growth

239 to a destructive phase portrayed by the recession of the land-sea margin (i.e. the delta shoreline).

240 In a second example, strong wave climates effectively diffuse fluvial sediment, thereby limiting

241 mouth bar growth and make the delta mainland more erosion prone, and vice versa. Therefore,

242 as per the above two examples, the delta shoreline and presence/absence of mouth bars can be

243 used as indicators to assess changes to river delta morphology.

244 Although there exist a plethora of morphology change indicators, it has to be noted that the focus

245 of this review will only be on, a) indicators that can be identified using satellite remote sensing

246 (e.g. shelf depth, (water depth reached by the submerged delta), although a factor governing delta

247 morphology, cannot be assessed using satellite remote sensing), and b) indicators that directly

248 reflect morphology-change of a delta (e.g. indicators reflecting changes to the effective deltaic

249 landmass (i.e. the shoreline)) as opposed to indicators of forcing factors which act as causal

250 factors of morphology change (e.g. drainage basin-averaged climate, which in turn can have an

251 effect on erosion of delta plain and sediment loading into feeder river).

252 Based on above selection criteria, we categorize all satellite-detectable indicators which reflect

253 morphology change into 5 classes summarized from studies conducted by Syvitski and Saito

254 (2007), Mathers and Zalasiewicz, (1999), Ulrich et al. (2009), Passalacqua, (2017). Table 1

255 provides an overview of these indicators, and the role they play in structuring the overall

256 morphology of the delta. 
This manuscript is a preprint and has been submitted for possible publication in Remote Sensing of Environment. This has not been peer reviewed before and is currently undergoing peer review for the first time. Please note that subsequent versions of this manuscript may have slightly different content based on reviewer comments. However, if accepted, the final version of this manuscript will be available via the 'Peer-reviewed Publication DOI' link on this webpage. Please feel free to reach out to the authors with suggestions/constructive feedback.

\begin{tabular}{|c|c|c|c|c|}
\hline Class & Indicator & Role of Indicator in Delta Morphology Change Representation & $\begin{array}{l}\text { Can be } \\
\text { Remotely } \\
\text { Sensed? } \\
(\mathrm{Y} / \mathrm{N})\end{array}$ & $\begin{array}{l}\text { Included in } \\
\text { Review? } \\
(\mathrm{Y} / \mathrm{N})\end{array}$ \\
\hline 1 & Shoreline & $\begin{array}{l}\text { Governs the land-sea margin, determines the effective landmass available for } \\
\text { human consumption, and determines subaerial view (plan view) of the delta. }\end{array}$ & $\mathrm{Y}$ & $\mathrm{Y}$ \\
\hline 2 & $\begin{array}{l}\text { Crevasse Splays and Channel } \\
\text { Avulsions }\end{array}$ & $\begin{array}{l}\text { Channel avulsions in deltaic areas start with the formation of a crevasse splay. } \\
\text { Crevasse splays (deposits of sediment in the shape of a fan or lobe formed by river } \\
\text { channels as a result of point failures of a levee) help better understand how rivers } \\
\text { naturally distribute water and sediment across floodplains, local rates of sediment } \\
\text { accumulation and sediment delivery to coastal regions, and influences on } \\
\text { floodplain topography and alluvial architecture, and help make informed decisions } \\
\text { on land-management solutions such as engineered diversions (Nienhuis et al., } \\
\text { 2018). }\end{array}$ & $\mathrm{Y}$ & $\mathrm{Y}$ \\
\hline 3 & $\begin{array}{l}\text { Number and Size of } \\
\text { Distributary Channels, and } \\
\text { Meander belts }\end{array}$ & $\begin{array}{l}\text { Avulsions and other channels on the delta make up the distributary network. } \\
\text { Proper understanding of the size of the distributary channels and the ways in } \\
\text { which they migrate through time is critical to many geomorphological and river } \\
\text { management problems on a delta (Seker et al., 2005; Yang et al., 1999). Channel } \\
\text { erosion and bank failure cause obstruction of navigation routes, changes to } \\
\text { channel geomorphology, and most importantly changes to flood levels which can } \\
\text { have adverse impacts on the infrastructure of the delta plain. }\end{array}$ & $\mathrm{Y}$ & $\mathrm{Y}$ \\
\hline 4 & $\begin{array}{l}\text { Barrier Islands, Beach Spits, } \\
\text { and Mouth Bars }\end{array}$ & $\begin{array}{l}\text { These are deltaic features that result from the dynamic interaction of fluvial } \\
\text { sediment supply and the redistribution of sediment by marine processes at the } \\
\text { river mouth-sea interface. Rapid deposition on river-mouth bars can cause their } \\
\text { seaward progradation, which, through the control of upstream siltation in the main } \\
\text { river channel, can serve as a stimulus to river channel migration. Heavy }\end{array}$ & $\mathrm{Y}$ & $\mathrm{Y}$ \\
\hline
\end{tabular}




\begin{tabular}{|c|c|c|c|c|}
\hline & & $\begin{array}{l}\text { sedimentation in the lower reaches of the river channel can also cause the riverbed } \\
\text { to aggrade and increases the flood risk on the floodplain, making the river channel } \\
\text { avulsion-prone. Beach spits and barrier islands function more in the capacity of } \\
\text { coastal storm surge attenuation and wave and tidal erosion control which impact } \\
\text { the shoreface. }\end{array}$ & & \\
\hline 5 & Gradient of Delta Plain & $\begin{array}{l}\text { Measured from the apex of the delta to the coast along the main channel (Syvitski } \\
\text { and Saito, 2007), the gradient of the delta plain is a vertical measure of } \\
\text { morphology. This in addition to the sediment supply to sediment retention on the } \\
\text { delta plain, can be significantly impacted by subsidence of the delta plain itself. } \\
\text { Subsidence related morphological changes to the gradient might not be reflected } \\
\text { by the land-sea boundary but can be reflective in flood extents during extreme } \\
\text { events which impact floodplain architecture. }\end{array}$ & $\mathrm{Y}$ & $* \mathrm{~N}$ \\
\hline
\end{tabular}

$260 *$ studies pertaining to the gradient of the delta plain will not be discussed in this review for two reasons. Firstly, the majority of the studies related to the gradient

261 in the literature are from a geological perspective without any substantial remote sensing component to them. Thus, they do not scope well within the constraints of this review. Secondly, even the studies that did discuss remotely sensed changes in river delta gradient, were done so as secondary derivatives of changes in 
264 The change in deltaic shoreline can be regarded as the most important environmental descriptor

265 of delta morphology, as it is the only parameter that reflects the 'quantity' of landmass available

266 for human consumption indicating how the delta front prograded or degraded over the years. In

267 comparison, other indicators detect morphology changes 'on' the deltaic landmass and thus has

268 garnered a lesser importance in literature (over $90 \%$ of the studies reviewed for morphology

269 change were based on the shoreline). Delta shoreline changes are described in section 3, and

270 studies discussing all other indicators are summarized in section 4.

\section{3. Delta Shoreline Change Detection Techniques}

272 Delta progradation/degradation determination through remote sensing relies on the varied

273 spectral response of the land-water boundary (i.e. the shoreline) at different wavelengths.

274 Different landforms produce characteristic surface spectral responses as products of the

275 combination of the terrain color and surface moisture linked with composite materials, texture

276 and structure properties of the exposed portions, terrain geometry and land cover. A large

277 number of techniques for delta progradation detection from satellite imagery have been

278 developed over the years and can be classified into three broad categories of change detection

279 methods (Figure 2): 1) Two-step Change Detection: use of a remote sensing technique(s) to

280 delineate morphology for a particular time step, use the same or different set of technique(s) to

281 retrieve morphology at a different time step and compare between them; 15 such techniques will

282 be discussed, 2) One-step change detection: The use of a remote sensing technique(s) on

283 multidate imagery to detect change in one step; two such techniques will be discussed: a) Layer

284 Arithmetic: use of band mathematics on the reflectance values to compare between multi-date

285 imagery, b) Change Vector Analysis: use of the radiometric properties of multi-date imagery to 
286 yield both magnitude and direction of change, and 3) Ensemble Classification: use of a mixed 287 methods approach.

288 It is important to note, and user applications need to pay attention to the fact that, the location of 289 a shoreline on a satellite image might not be the topographical boundary between land and water 290 as it is an instantaneous one influenced by seawater level fluctuations caused by waves, tides and 291 local seasonal sea level changes. Therefore, it would be erroneous to apply said shoreline 292 detection techniques to a single image representative of a time step, as these external forces can 293 substantially affect water levels (Walker and Hammack, 2000) and consequently the boundary, 294 without necessarily indicating a morphological change. There are statistical methods to correct 295 for the shoreline position (Zhang et al., 2018) if changes of shorter time steps are desired (e.g. 296 change every year during a 5-year period). For longer time scale analysis (e.g. change every 5 297 years for a 30-year period), a composite, representative of the deltaic region, using imagery over 298 a few consecutive months (e.g. 6 months), is created, and the averaged raster is used as a single 299 time step. 


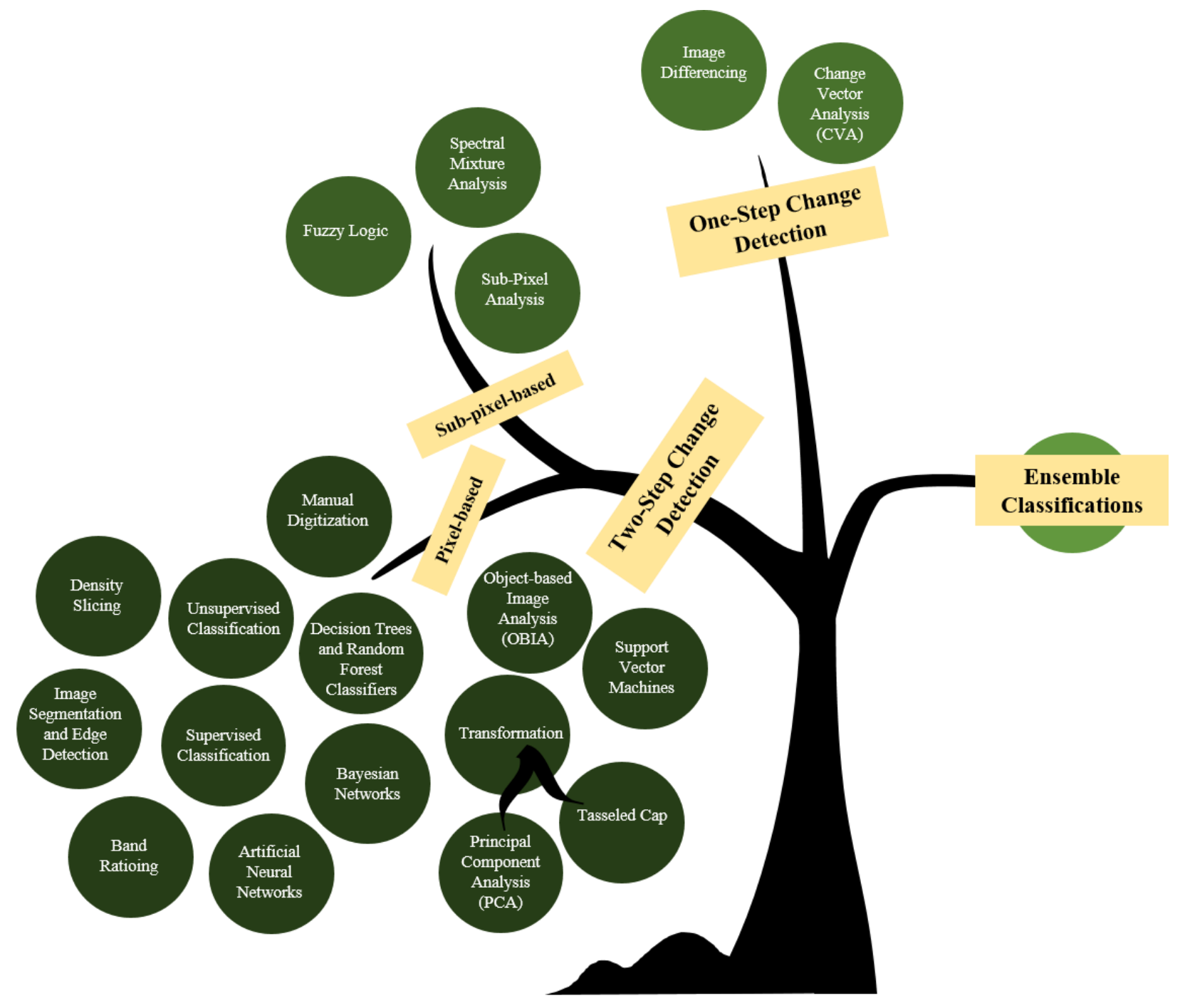

301 Figure 2: Classification of remote sensing techniques used for river delta morphology change detection

303 The discussion of each technique is framed on the conceptual background of the technique, how 304 and why it is applied to deltaic feature detection, the technical merit of application, and its 305 caveats informed by the conclusions and recommendations of the literature reviewed. We present 306 a summary of all techniques reviewed in this paper along with example studies in Table 2 below 307 for the readership to revert to, during the length of the document, as a quick reference guide. 
Table 2: A summary of remote sensing techniques of river delta morphology change identification

\begin{tabular}{|c|c|c|c|}
\hline Technique & Example Studies & River Delta (Country) & Satellite Platform \\
\hline Manual Digitization & $\begin{array}{l}\text { Yang (1996) } \\
\text { Yang et al. (1999) } \\
\text { Chu et al. }(2006) \\
\text { Zhao et al. }(2008) \\
\text { Marghany et al. (2010) } \\
\text { El Asmar and Hereher (2011) } \\
\text { Kuenzer } \text { et al. } \text { (2014) } \\
\text { Duţu } \text { et al. }(2014) \\
\text { Ahmed } \text { et al. } \text { (2018) }\end{array}$ & $\begin{array}{l}\text { Yellow (China) } \\
\text { Yellow (China) } \\
\text { Yellow (China) } \\
\text { Yangtze (China) } \\
\text { Kuala Terengganu (Malaysia) } \\
\text { Nile (Egypt) } \\
\text { Yellow (China) } \\
\text { Danube (Romania/Ukraine) } \\
\text { Ganges-Brahmaputra-Meghna (India) }\end{array}$ & $\begin{array}{l}\text { Landsat MSS, Landsat TM } \\
\text { Landsat MSS, Landsat TM } \\
\text { Landsat MSS, Landsat TM } \\
\text { Landsat TM, Landsat ETM+ } \\
\text { ERS-1, RADARSAT-1 } \\
\text { Landsat MSS, Landsat TM, SPOT-4 } \\
\text { Landsat MSS, Landsat TM } \\
\text { Landsat TM, Landsat ETM+ } \\
\text { Landsat TM, Landsat ETM+ }\end{array}$ \\
\hline Density Slicing & $\begin{array}{l}\text { Mouchot et al. (1991) } \\
\text { Mathers and Zalasiewicz (1999) } \\
\text { Ryu et al. (2002) } \\
\text { Maiti and Bhattacharya (2009) } \\
\text { Mallinis et al. (2011) } \\
\text { Allen et al. (2012) } \\
\text { Kong et al. (2015) } \\
\text { Ghoneim et al. }(2015) \\
\text { Dada } \text { et al. } \text { (2018) }\end{array}$ & $\begin{array}{l}\text { Mackenzie (Canada) } \\
\text { Red (Vietnam) } \\
\text { Gosmo Bay (Korea) } \\
\text { Subarnarekha and Rasulpur (India) } \\
\text { Nestos (Greece) } \\
\text { Wax Lake (USA) } \\
\text { Yellow (China) } \\
\text { Nile (Egypt) } \\
\text { Niger (Nigeria) }\end{array}$ & $\begin{array}{l}\text { Landsat TM } \\
\text { Landsat TM } \\
\text { Landsat TM, ASTER } \\
\text { Landsat MSS, Landsat TM, Landsat ETM+, ASTER } \\
\text { Quickbird } \\
\text { Landsat TM, Landsat ETM+ } \\
\text { Landsat MSS, Landsat TM, Landsat ETM+ } \\
\text { Landsat MSS, Landsat TM, Landsat ETM+ } \\
\text { Landsat TM, Landsat ETM+ }\end{array}$ \\
\hline $\begin{array}{l}\text { Image Segmentation } \\
\text { and Edge Detection }\end{array}$ & $\begin{array}{l}\text { Lee and Jurkevich (1990) } \\
\text { Mason and Davenport (1996) } \\
\text { Niedermeier } \text { et al. (2000) } \\
\text { Bayram et al. } \text { (2008) } \\
\text { Al Fugura et al. }(2011)\end{array}$ & $\begin{array}{l}\text { Chesapeake Bay (USA) } \\
\text { Wash delta/estuary (UK) } \\
\text { Elbe (Germany) } \\
\text { Bhosporous (Turkey) } \\
\text { Kuala Terrenganu (Malaysia) }\end{array}$ & $\begin{array}{l}\text { Saesat, Shuttle Imaging Radar (SIR) } \\
\text { ERS-1 } \\
\text { ERS-1 and ERS-2 } \\
\text { Corona, IRS-1D, Landsat ETM+ } \\
\text { RADARSAT-1 }\end{array}$ \\
\hline Band Ratioing & $\begin{array}{l}\text { Yang et al. (1999) } \\
\text { El-Raey et al. }(1999) \\
\text { Ryu et al. }(2002)\end{array}$ & $\begin{array}{l}\text { Yellow (China) } \\
\text { Nile (Egypt) } \\
\text { Gosmo Bay (Korea) }\end{array}$ & $\begin{array}{l}\text { Landsat MSS, Landsat TM } \\
\text { Landsat MSS } \\
\text { Landsat TM, ASTER }\end{array}$ \\
\hline
\end{tabular}




\begin{tabular}{|c|c|c|c|}
\hline & $\begin{array}{l}\text { Guariglia et al. (2006) } \\
\text { Ekercin (2007) } \\
\text { Kuleli (2010) } \\
\text { Cui and Li (2011) } \\
\text { Mukhopadhyay et al. (2012) } \\
\text { Niya et al. (2013) } \\
\text { Kundu et al. (2014) } \\
\text { Louati et al. (2015) } \\
\text { Nitze and Grosse (2016) } \\
\text { Sun et al. (2018) } \\
\text { Wang et al. (2019) } \\
\text { Da Silva et al. (2019) } \\
\text { Viaña-Borja and Ortega-Sánchez } \\
\text { (2019) }\end{array}$ & $\begin{array}{l}\text { Ionian coast (Italy) inclusive of deltas } \\
\text { nothern coast of Turkey including deltas } \\
\text { Cukurova (Turkey) } \\
\text { Yellow (China) } \\
\text { Puri coast and Mahanadi (India) } \\
\text { Dalaki (Iran) } \\
\text { Sagar Island, GBM (India) } \\
\text { Medjerda (Tunisia) } \\
\text { Lena (Russia) } \\
\text { Yangtze (China) } \\
\text { Yellow (China) } \\
\text { Parnaíba (Brazil) } \\
\text { Guadalfeo, Adra, and Ebro (Spain) }\end{array}$ & $\begin{array}{l}\text { Landsat TM, Landsat ETM+, SPOT XS, Corona } \\
\text { Landsat MSS, Landsat TM, Landsat ETM+ } \\
\text { Landsat TM } \\
\text { Landsat MSS, Landsat TM, Landsat ETM+ } \\
\text { Landsat TM } \\
\text { Landsat TM } \\
\text { Landsat TM } \\
\text { Landsat TM, Landsat ETM+, Landsat OLI } \\
\text { Landsat TM, Landsat ETM+, Landsat OLI } \\
\text { Landsat MSS, TM, OLI, GF-1 PMS, SPOT-7 } \\
\text { Landsat TM, Landsat OLI } \\
\text { Landsat MSS, TM, ETM+, OLI } \\
\text { Landsat TM, Landsat ETM+, Landsat OLI }\end{array}$ \\
\hline $\begin{array}{l}\text { Unsupervised } \\
\text { Classification }\end{array}$ & $\begin{array}{l}\text { Wilson (1997) } \\
\text { Frihy } \text { et al. (1998) } \\
\text { Guariglia } \text { et al. (2006) } \\
\text { Ekercin (2007) } \\
\text { Nath and Deb (2010) } \\
\text { Mukhopadhyay } \text { et al. (2012) } \\
\text { Muster } \text { et al. (2012) } \\
\text { Kundu et al. (2014) } \\
\text { Buono et al. (2017) }\end{array}$ & $\begin{array}{l}\text { Fitzroy (Australia) } \\
\text { Nile (Egypt) } \\
\text { Ionian coast (Italy) inclusive of deltas } \\
\text { nothern coast of Turkey including deltas } \\
\text { Okavango Delta (Botswana) } \\
\text { Puri coast and Mahanadi (India) } \\
\text { Lena (Russia) } \\
\text { Sagar Island of the GBM (India) } \\
\text { Yellow (China) }\end{array}$ & $\begin{array}{l}\text { Corona } \\
\text { Landsat MSS, Landsat TM } \\
\text { Landsat-TM, Landsat ETM+, SPOT-PX/XS, Corona } \\
\text { Landsat MSS, Landsat TM, Landsat ETM+ } \\
\text { AVHRR } \\
\text { Landsat TM } \\
\text { Proba -1 } \\
\text { Landsat TM } \\
\text { RADARSAT-2 }\end{array}$ \\
\hline $\begin{array}{l}\text { Supervised } \\
\text { Classification }\end{array}$ & $\begin{array}{l}\text { Sgavetti and Ferrari (1988) } \\
\text { Ciavola } \text { et al. } \text { (1999) } \\
\text { Seker } \text { et al. (2003) } \\
\text { El-Kawya } \text { et al. (2011) } \\
\text { Masria et al. (2015) }\end{array}$ & $\begin{array}{l}\text { Po and Adige (Italy) } \\
\text { Shkumbini, Semani and Vjosë (Albania) } \\
\text { Riva (Turkey) } \\
\text { Nile (Egypt) } \\
\text { Nile (Egypt) }\end{array}$ & $\begin{array}{l}\text { Landsat TM } \\
\text { Landsat TM } \\
\text { Landsat MSS, Landsat TM, Landsat ETM+ } \\
\text { Landsat TM, Landsat ETM+ } \\
\text { Landsat TM, Landsat ETM+ }\end{array}$ \\
\hline
\end{tabular}




\begin{tabular}{|c|c|c|c|}
\hline $\begin{array}{l}\text { Transformation } \\
\text { Methods } \\
\text { Principal Component } \\
\text { Analysis (PCA) }\end{array}$ & $\begin{array}{l}\text { El Raey et al. (1995) } \\
\text { Li and Yeh (1998) } \\
\text { Kushwaha } \text { et al. (2000) } \\
\text { Seto et al. (2002) } \\
\text { Li and Yeh (2004) } \\
\text { Ghanavati et al. (2008) } \\
\text { Ghoneim et al. (2015) } \\
\text { Nandi et al. (2016) } \\
\text { Chen } \text { et al. (2019) }\end{array}$ & $\begin{array}{l}\text { Nile (Egypt) } \\
\text { Pearl (China) } \\
\text { West Bengal coast inclusive of deltas (India) } \\
\text { Pearl (China) } \\
\text { Pearl (China) } \\
\text { Hendijan (Iran) } \\
\text { Nile (Egypt) } \\
\text { Sagar Island, GBM (India) } \\
\text { Yangtze (China) }\end{array}$ & $\begin{array}{l}\text { Landsat MSS, Landsat TM } \\
\text { Landsat TM } \\
\text { ERS-1 } \\
\text { Landsat TM } \\
\text { Landsat TM } \\
\text { Landsat TM, Landsat ETM+ } \\
\text { Quickbird, Worldview-2 } \\
\text { Landsat MSS, Landsat TM, Landsat ETM+ } \\
\text { Landsat OLI }\end{array}$ \\
\hline $\begin{array}{l}\text { Artificial Neural } \\
\text { Networks (ANN) }\end{array}$ & $\begin{array}{l}\text { Berberoglu et al. (2000) } \\
\text { Zhu (2001) } \\
\text { Del Frate et al. (2012) } \\
\text { Ding (2013) }\end{array}$ & $\begin{array}{l}\text { Cukurova (Turkey) } \\
\text { Pearl (China) } \\
\text { Italian coastline inclusive of deltas } \\
\text { Yellow (China) }\end{array}$ & $\begin{array}{l}\text { Landsat TM } \\
\text { Landsat MSS, Landsat TM } \\
\text { COSMO-SkyMed } \\
\text { Landsat TM, Landsat ETM+ }\end{array}$ \\
\hline $\begin{array}{l}\text { Decision Trees and } \\
\text { Random Forest } \\
\text { Classifiers }\end{array}$ & $\begin{array}{l}\text { Ottinger et al. (2013) } \\
\text { Kuenzer et al. }(2014) \\
\text { Haas and Bun (2014) } \\
\text { Banks et al. }(2015) \\
\text { Berhane et al. }(2018)\end{array}$ & $\begin{array}{l}\text { Yellow (China) } \\
\text { Niger (Nigeria) } \\
\text { Yellow, Pearl (China) } \\
\text { Kitikmeot region (Canada) inclusive of deltas } \\
\text { Selenga (Russia) }\end{array}$ & $\begin{array}{l}\text { Landsat TM } \\
\text { Landsat TM, Landsat ETM+ } \\
\text { Landsat TM, HJ-1A/B satellites } \\
\text { RADARSAT-2, Landsat TM } \\
\text { Worldview-2 }\end{array}$ \\
\hline Bayesian Networks & $\begin{array}{l}\text { Gutierrez et al. (2011) } \\
\text { Yates and Cozannet (2012) }\end{array}$ & $\begin{array}{l}\text { U.S. Atlantic Coast inclusive of deltas } \\
\text { European coasts inclusive of deltas }\end{array}$ & Areal observations used as input \\
\hline $\begin{array}{l}\text { Support Vector } \\
\text { Machines }\end{array}$ & $\begin{array}{l}\text { Xu et al. (2012) } \\
\text { Masria et al. (2015) } \\
\text { Petropoulos et al. (2015) } \\
\text { Gou et al. (2016) }\end{array}$ & $\begin{array}{l}\text { Yellow (China) } \\
\text { Nile (Egypt) } \\
\text { Axios and Aliakmonas (Greece) } \\
\text { Yellow (China) }\end{array}$ & $\begin{array}{l}\text { RADARSAT-2 } \\
\text { Landsat TM, Landsat ETM+ } \\
\text { Landsat TM } \\
\text { ALOS-2 }\end{array}$ \\
\hline
\end{tabular}




\begin{tabular}{|c|c|c|c|}
\hline $\begin{array}{l}\text { Object-based Image } \\
\text { Analysis }\end{array}$ & $\begin{array}{l}\text { Cao et al. }(2007) \\
\text { Liu et al. }(2014) \\
\text { Demers } \text { et al. }(2015) \\
\text { Zhu et al. }(2018)\end{array}$ & $\begin{array}{l}\text { Yellow (China) } \\
\text { Yellow (China) } \\
\text { Islands of Mackenzie Delta (Canada) } \\
\text { Yellow (China) }\end{array}$ & $\begin{array}{l}\text { SPOT } 5 \\
\text { Landsat TM, Landsat ETM+, HJ-1A/B satellites } \\
\text { RADARSAT-2 } \\
\text { Landsat MSS, Landsat TM, Landsat OLI }\end{array}$ \\
\hline Fuzzy Logic & $\begin{array}{l}\text { Dellepiane } \text { et al. }(2004) \\
\text { Foody et al. }(2005) \\
\text { Ghanavati } \text { et al. }(2008) \\
\text { Dewi et al. }(2016)\end{array}$ & $\begin{array}{l}\text { coastline in Genova (Italy) inclusive of deltas } \\
\text { coast in Terengganu (Malaysia) inclusive of deltas } \\
\text { Hendijan (Iran) } \\
\text { deltaic region in the Sayung District (Indonesia) }\end{array}$ & $\begin{array}{l}\text { ERS-1, ERS-2 } \\
\text { IKONOS } \\
\text { Landsat TM, Landsat ETM+ } \\
\text { Landsat TM, Landsat ETM+, Landsat OLI }\end{array}$ \\
\hline $\begin{array}{l}\text { Spectral Mixture } \\
\text { Analysis }\end{array}$ & $\begin{array}{l}\text { Liu et al. (2016) } \\
\text { Liu et al. (2017) }\end{array}$ & $\begin{array}{l}\text { Yellow (China) } \\
\text { Pearl (China) }\end{array}$ & $\begin{array}{l}\text { Landsat OLI } \\
\text { Landsat OLI } \\
\end{array}$ \\
\hline Sub-Pixel Analysis & Wei et al. (2008) & Yellow (China) & ASTER \\
\hline Image Differencing & $\begin{array}{l}\text { Yeh and Li (1997) } \\
\text { Xia (1998) } \\
\text { El-Raey et al. (1999) } \\
\text { Adegoke (2010) }\end{array}$ & $\begin{array}{l}\text { Pearl (China) } \\
\text { Pearl (China) } \\
\text { Nile (Egypt) } \\
\text { Niger (Nigeria) }\end{array}$ & $\begin{array}{l}\text { Landsat MSS, Landsat TM } \\
\text { Landsat TM } \\
\text { Landsat MSS } \\
\text { Landsat TM, Landsat ETM+ }\end{array}$ \\
\hline $\begin{array}{l}\text { Change Vector } \\
\text { Analysis }\end{array}$ & $\begin{array}{l}\text { El-Raey et al. (1999) } \\
\text { Seto et al. (2002) }\end{array}$ & $\begin{array}{l}\text { Nile (Egypt) } \\
\text { Pearl (China) }\end{array}$ & $\begin{array}{l}\text { Landsat MSS } \\
\text { Landsat TM }\end{array}$ \\
\hline
\end{tabular}




\section{1 (A) Pixel-Based Methods}

\subsubsection{Manual Digitization}

330 Deltaic coastlines are delineated manually based on the delineator's/digitizer's knowledge of the 331 morphological features, vegetation and sediment characteristics of the delta. Compared to

332 computer aided classification techniques, manual operation takes advantage of the judgment

333 skills and interpretation of humans in defining what and where the boundary is between land and 334 water.

335 The combination of digitization and automatic boundary detection algorithms (discussed later) to

336 detect the land-ocean shoreline boundaries were proven to be successful (Kong et al., 2015).

337 However, this technique has several inherent problems. In addition to the inaccuracies induced 338 through the monotonous nature of digitization, it is also challenging for the human eye to 339 interpret the boundary (based largely on digitizer's experience) since, mainly in low-resolution 340 images, color shades may decay gradually (Niedermeier et al., 2005). Presence of water 341 saturated zones in the vicinity of the land water boundary could complicate the issue. Therefore, 342 calculations have to be performed in order to recognize if the inaccuracies constitute a significant 343 source of error in comparison to the magnitude of the overall changes in the delta (Chu et al., 344 2006). This approach is also highly time-consuming and tedious. It is therefore expensive (labor 345 cost) and ineffective when a large number of images need to be analyzed. 


\subsubsection{Density Slicing}

347 The concept of density slicing involves classifying the remotely-sensed image into land and sea,

348 often by identifying a threshold value for a single spectral band. In order to determine this

349 critical threshold without bias, a histogram analysis is often performed (Figure 3). Ryu et al.

350 (2002) and Shen et al. (2008) showed that in tidal flat zones, thermal-infrared (TIR) band is the

351 most sensitive to the location of waterline through density slicing. Work on Landsat has shown

352 that mid-infrared bands (band 5 in the case of Landsat TM) is the most suitable for extracting the

353 land water interface because it exhibits a strong contrast between land and water features due to

354 the high degree of absorption of the mid-infrared wavelength by water (Manavalan et al., 1993;

355 Kelly et al., 1998; Frazier and Page, 2000; Lee et al., 2001; Alesheikh et al., 2007).

356 While overall successful, this method carries with it certain caveats. Although land and water

357 generally appear to be spectrally separable, the accuracy of waterline prediction is sometimes

358 low due to the dynamic and complex land-water interactions in coastal deltaic regions. This

359 could be due to spectral confusion, arising from effects such as variable depth and turbidity,

360 together with the spatial resolution of the imagery, which influences the clarity of boundaries and

361 proportion of mixed pixels, limiting the accuracy of shoreline mapping (Frazier and Page, 2000;

362 Ryu et al., 2002; Malthus and Mumby, 2003). Also, the use of one spectral band usually does not

363 allow every type of change to be detected (Gong, 1993). Density slicing alone is not sufficient in

364 determining the shoreline and, therefore, typically used in conjunction with other methods to

365 obtain higher delta shoreline classification accuracies (Marghany et al., 2010). 


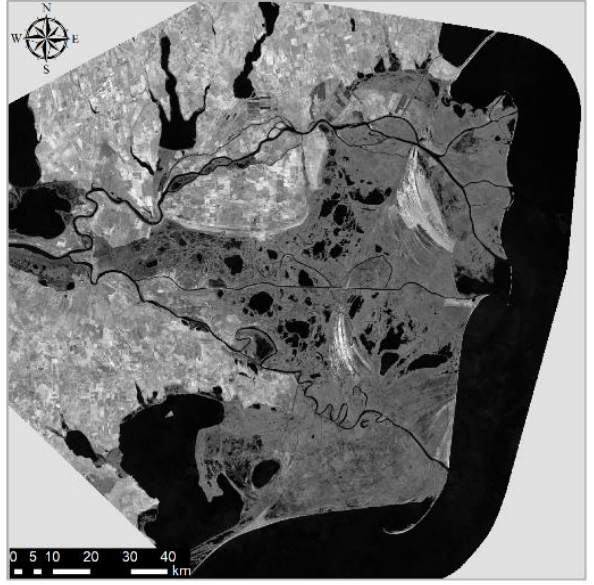

(a) Landsat TM 5 band

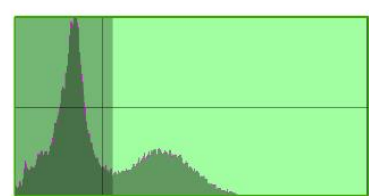

(b) Hlistogram used to determine thresholds

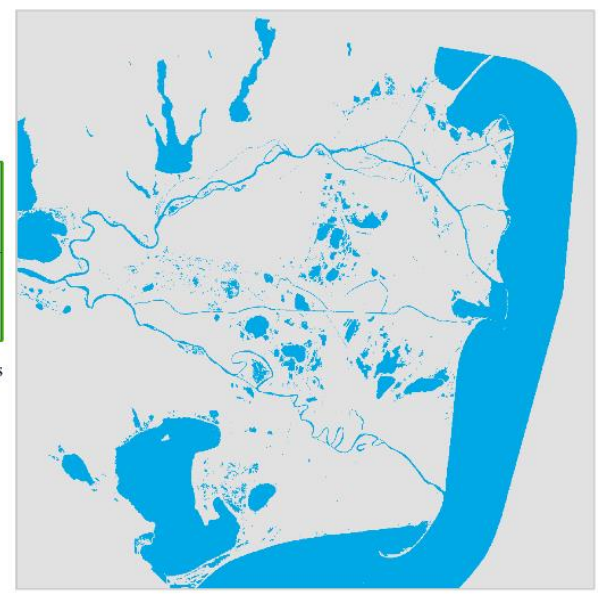

(b) Density-sliced raster with water features in bluc

Figure 3: Density Slicing of band 5 (Landsat TM) of the Danube delta region to obtain a land-water raster. The shoreline was subsequently extracted using GIS methods.

\subsubsection{Image Segmentation and Edge Detection}

371 Image segmentation and edge detection algorithms follow the process of manual digitization

372 more closely by dividing an image into different regions where sharp intensity alterations occur.

373 The "alternative connective approach", one of two major image segmentation and edge detection

374 algorithms is used in deltaic research where it seeks to grow homogeneous regions by merging 375 pixels or sub-regions on the basis of some similarity criterion (Lemoigne and Tilton, 1995). This

376 approach is based on 'guiding' the remote sensing software by manually identifying points along

377 the shoreline of the original image. The software then examines the edges of the image following

378 these points. The parameters by which the shoreline is identified are determined by the analyst.

379 This heuristic search is found to be faster and more reliable than entirely automated approaches 380 (Loos and Niemann, 2002) due to the input of previously gathered information by the analyst. 
381 Albeit its success, this method also has its limitations in possible inclusion of different earth

382 feature classes into the same region, making spectral separation and subsequent identification of

383 thematic information classes difficult. As White and El Asmar (1999) and Heimann et al. (2004)

384 stated, since the classical region growing methods (classifying neighboring pixels outward from

385 a point of origin based on similarity of reflectance of the originating pixel) yield outcomes in

386 accordance with the contrast of the image, contrast similarities between land and water zones

387 impedes the extraction of coastline from other existing constituents and could result in

388 irregularities of coastline extractions.

\subsubsection{Band Ratioing}

390 This method exploits the near infrared (NIR) and short-wave infrared (SWIR) bands whose

391 wavelengths are absorbed by water, resulting in surface water rendered as black color in the

392 processed image. A combination of these spectral bands ((NIR-SWIR)/(NIR+SWIR)) is used to

393 reduce the effect of suspended sediment near shorelines (Lohani \& Mason, 1999; Lodhi et al.,

394 1997) and accentuate higher reflectance characteristics from soil and healthy vegetation,

395 providing a context for the land/water interface (Braud and Feng, 1998; Fraizer and Page, 2000;

396 Guariglia et al., 2006). In comparison to other methods, ratioing is a relatively rapid means of

397 identifying areas of change.

398 However, there are certain downsides to this method. The Band 2/Band 5 ration has a value

399 greater than one for water and less than one for land in large areas of the coastal zone (Alesheikh

400 et al., 2007). Image processing software use this ratio as an algorithm for separating water from

401 land from TM or ETM+ imagery. This ratio works well in coastal zones covered by soil, but not

402 in land with vegetative cover. This can lead to mistakenly classifying other land use types as

403 water (Alesheikh et al., 2007). Therefore, this is a readily go-to method if the aim is to rapidly 


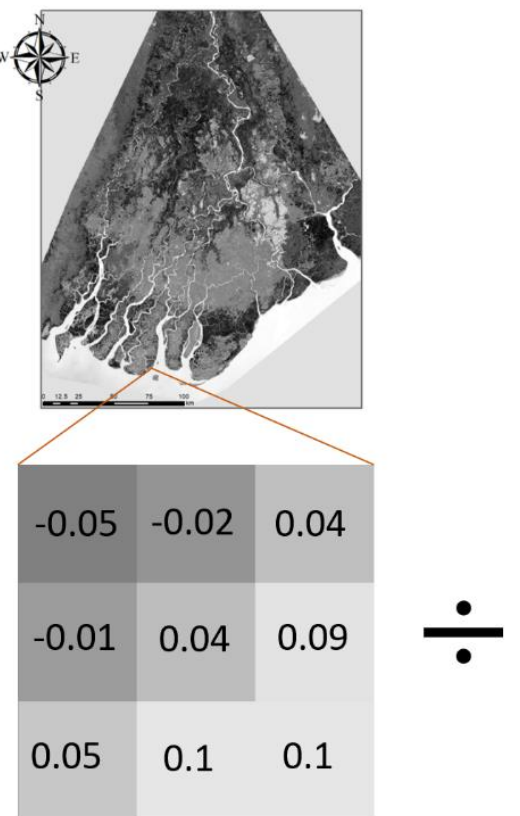

(Green - SWIR)

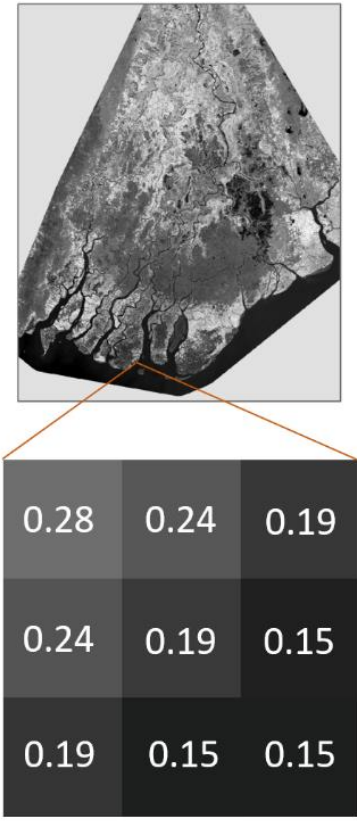

(Green + SWIR)

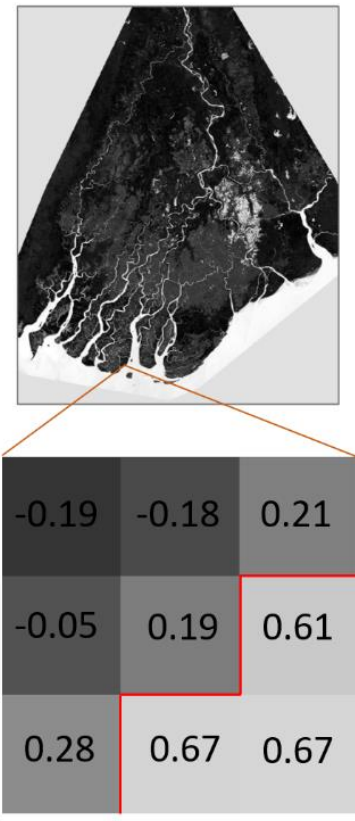

MNDWI Raster

Figure 4: Band ratioing of Landsat-OLI imagery of the Irrawaddy river delta to produce a landwater raster after which the shoreline is extracted using GIS methods. The combination and ratio used here is the Modified Normalized Water Index (MNDWI; Xu, 2006) used to accentuate water features. left: A subtracted difference raster of Band 6 (SWIR) is and Band 3 (Green) is generated (the blow-up denotes raster values of the selected region). Middle: An added difference raster of Band 6 (SWIR) is and Band 3 (Green) is generated. Right: The difference-rasters are ratioed to produce the MNDWI feature-accentuated raster.

\subsubsection{Unsupervised Classification}

Unsupervised classification is an effective method of natural clustering and extracting land-cover information of remotely sensed image data based on spectral properties of pixels. Compared to supervised classification (discussed in 3.1.6), unsupervised classification requires minimal initial 
418 input from the analyst (determining the clustering algorithm and desired number of classes) as it

419 does not require training data. The clustering process results in a classification map consisting of

$420 n$ spectral classes. The analyst then attempts to assign or transform the spectral classes into

421 thematic information classes of interest (e.g., forest, agriculture). Many clustering algorithms

422 have been developed to date (e.g. ISODATA Clustering, K-Means).

423 Unsupervised methods, although not completely exempt from the user's interaction, require less

424 inputs than their supervised counterparts and is computationally efficient. However, the user

425 must have knowledge of the area and understand the spectral characteristics of the terrain in

426 order to relate the classes to actual land cover types (such as water features, wetlands, developed

427 areas, coniferous forests, etc.). Difficulties in obtaining consistent classes from images taken at

428 different times, owing to variability in illumination, atmospheric effects, and instrumental

429 response, have been reported (Adams et al., 1995). Also, some spectral clusters may be

430 meaningless because they represent mixed classes of earth surface materials. It has been noted in

431 the literature that although the use of unsupervised classification is nearly a labor-independent

432 analysis, this technique does not lead to the most detailed analysis and cannot produce the

433 highest classification accuracy (Congalton, 1991; Xia, 1998; Enderle and Weih, 2005).

\section{$434 \quad 3.1 .6 \quad$ Supervised Classification}

435 In Supervised classification, the analyst selects sample pixels in an image that are representative

436 of land cover classes, and then directs the image processing software to use these end-member

437 pixels (training pixels) as references for the classification of all other pixels in the image

438 (determination of maximum likelihood of image pixels of a land use class based on training

439 data). Training sites are selected based on the analyst's knowledge and experience of image

440 interpretation. The analyst also designates the number of classes that the image is classified into. 
441 Since supervised classification is based on prior knowledge about the land cover and their typical

442 spectral characteristics by the analyst, this method is deemed one of the more successful methods

443 of delta morphology detection and is commonly used as a benchmark to test other algorithms

444 (Khatami et al., 2016). Higher classification accuracies resulting from supervised classification

445 motivated researchers to combine this technique with other methods. Shalaby and Tateishi

446 (2007), for example, concluded that the use a combination of supervised classification and visual

447 interpretation analysis increased the overall classification accuracy by approximately $10 \%$.

448 However, as the training sites are selected based on the knowledge and experience of the analyst, 449 there is always the possibility that the sample pixels that one selects for a given information class 450 (e.g. shoreline) will not be homogenous across the entire study domain (i.e. training areas will 451 not encompass unique spectral signatures of a particular land feature). In addition, since this is a 452 user driven method, it can be a time consuming and an exhaustive one, if done for multiple time 453 steps over different study domains.

\section{$454 \quad 3.1 .7$ Transformation methods}

455 When multispectral images are used to detect change of delta morphology, a reduction of the 456 number of bands is often warranted in order to identify dominant patterns in the imagery (i.e. 457 enhance the original classification feature space) without compromising the variance. Although 458 simple band mathematics can be used and is straightforward (e.g. density slicing, band ratioing), 459 it can be inefficient when the number of spectral bands of the image exceeds three. To overcome 460 these difficulties the process of image transformation was introduced. Different transformation 461 methods have been developed over the years, and two of those have been reported in delta 462 morphological studies: Principal Component Analysis (PCA) and Tasseled Cap Analysis (TCA). 
463 The central concept of a PCA is to reduce the dimensionality of a dataset consisting of many 464 interrelated variables, while retaining as much variation present in the dataset as possible. This is 465 achieved by transforming the data to a new set of variables (principal components) which are 466 uncorrelated and ordered so that the first few retain most of the variation present in all the 467 original variables (Deng et al., 2008). The procedure works as such that subsequent to 468 performing a PCA on multi temporal imagery, conventional clustering methods (e.g. 469 unsupervised) can be applied to the first few principal components to produce thematic maps 470 representative of different earth features. This method was shown to improve accuracy gains 471 when utilized with other techniques in the image classification process (Khatami et al., 2016).

472 Although comparatively PCA analysis has advantages over simple band mathematics techniques 473 (i.e. band ratioing, band differencing), it introduces difficulties in interpreting and labeling each 474 component image (to associate physical scene characteristics with the individual components). 475 This type of analysis is also scene dependent and is difficult to obtain the 'from-to change' class 476 information (change in pixel information from an earlier time step to a later one) when detecting 477 change over multiple time steps. Moreover, it was found that the application of PCA for multiple 478 time step analysis is subject to the condition that the areas of change must be a small proportion 479 of the entire study area (Gong, 1993; Seto et al., 2002).

480 TCA transformation rotates multispectral data and creates three planes: Brightness (B), 481 Greenness (G) and Wetness (W) (Crist, 1985). The Brightness band is a weighted sum of all 482 reflective bands and can be interpreted as the overall brightness or albedo at the earth's surface. 483 The Greenness band primarily measures the contrast between the visible bands and near-infrared 484 bands and is similar to a vegetation index. The wetness band measures the difference between 485 the weighted sum of the visible and near-infrared bands and the mid-infrared bands and is a 
486 proxy of plant and/or soil moisture (Seto et al., 2002). In TCA, the brightness, greenness,

487 wetness bands are directly associated with physical scene attributes and therefore easily

488 interpreted (Figure 5). TCA analyses to detect delta morphological change is seldom carried out

489 alone and is used as a data reduction technique prior to the data being analyzed by another

490 technique(s). Examples of the usage of TCA is given in section 4.3.

491
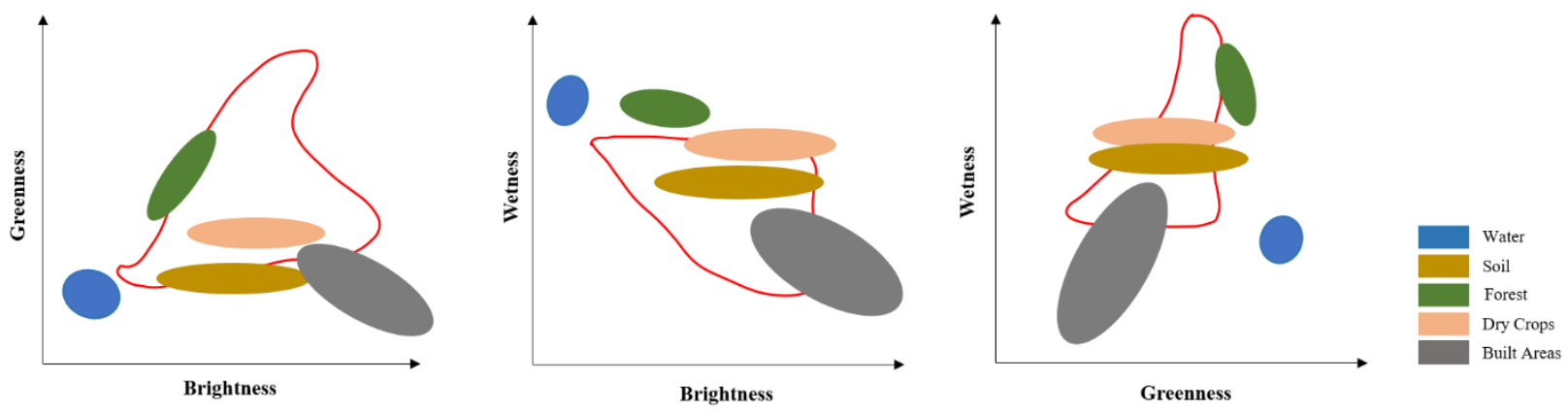

492 Figure 5: A typical representation of earth features between correlations of the three transformed

493 bands.

\subsubsection{Artificial Neural Networks (ANN)}

495 Artificial Neural Networks (ANN), a form of Artificial Intelligence (AI), can be used to semi496 automate image classification, and has become a common alternative to conventional band

497 statistical approaches. The development of ANNs was inspired from human brain recognition 498 and brain learning mechanisms (Berberoglu et al., 2000). Neural networks consist of input and 499 output layers, as well as (in most cases) a hidden layer consisting of units that transform the input 500 into something that the output layer can use (Foody et al., 1995). They are excellent tools for

501 finding patterns which are far too complex or numerous for a human programmer to extract and 502 train the machine to recognize (Samarasinghe, 2016). 
503 The backpropagation algorithm (Paola and Schowengerdt, 1995) is the most common method of 504 training multi-layer networks to date (Samarasinghe, 2016), with an emphasis on its application 505 to pattern recognition in multispectral imagery. It allows networks to adjust their hidden layers of 506 neurons in situations where the outcome does not match what the user is hoping for 507 (Samarasinghe, 2016), similar to a network designed to recognize muddy shores, and 508 misidentifies them as turbid waters.

509 As delta evolution is a very intricate non-linear process influenced by many factors such as the 510 coming water and sediment discharges and coastal dynamics, neural networks possess great 511 robustness over traditional classifiers as neural networks are also inherently nonparametric 512 nature. The strengths of a neural network lie in arbitrary decision boundary capabilities (the 513 ability to partition the data set into separate classes effectively), easy adaptation to different types 514 of data and input structures, possibility of fuzzy output values (probability of a pixel belonging to 515 a certain information class type) that can enhance classification accuracies (classification 516 accuracies of fuzzy outputs are discussed in the Fuzzy logic section), and good generalization for 517 use with multiple images. Land/water rasters created using neural networks are later used with 518 GIS methods to extract deltaic shorelines. The disadvantages of the method are inconsistent 519 results due to random initial weights, the requirement of obscure initialization values (e.g., 520 learning rate and hidden layer size: the "black box," phenomenon in which the user feeds in data 521 and receives answers, and no access to the exact decision making process), slow training time of 522 the network, and heavy computational demand to train the network for large datasets (Xie et al. 523 2008). For a detailed analysis of advantages and disadvantages of neural networks for remote 524 sensing applications, the readers are referred to Jarvis and Stuart (1996) and Mas and Flores 525 (2008). We can conclude from the literature that although the neural network method has several 
526 unique capabilities, it will become a useful tool in remote sensing only if it is made faster, more

527 predictable, and easier to implement.

\section{$528 \quad 3.1 .9$ Decision Trees and Random Forest Classifiers}

529 A Decision Tree is a tree-structure like flowchart (Friedl and Brodley, 1997; Figure 6). There are 530 many different types of decision tree algorithms, e.g. Classification and Regression Tree 531 Algorithm (CART; Denison et al., 1998), C4.5 (Mazid et al., 2010).

532 Decision Trees are easy to interpret, their internal workings are capable of being observed, 533 making it possible to reproduce work, while making no statistical assumptions regarding the

534 distribution of data (Hass and Bun, 2014). They are also computationally efficient (Friedl and 535 Brodley, 1997), and perform well on large multispectral datasets (Zhang et al., 2017).

536 One of the major problems with using decision trees is overfitting, especially when a tree is 537 particularly deep (Friedl and Brodley, 1997; Pal and Mather, 2003). Over-fitting occurs when the 538 tree is designed so as to perfectly fit all samples in the training data set, resulting in branches 539 with strict rules of sparse data. This affects the accuracy when predicting samples that are not 540 part of the training set (i.e. yields highly accurate output for the training data but low accuracy 541 for test data).

542 Random Forest (RF) classifiers mitigate this problem well. First proposed by Breiman (2001), a $543 \mathrm{RF}$ is simply a collection of decision trees whose results are aggregated into one final result.

544 Their ability to limit over-fitting without substantially increasing error due to bias makes them a 545 powerful model. In a random forest, the number of trees in the forest (n estimators), and the 546 maximum number of features to be used in each tree can be specified. However, one cannot 547 control the randomness over which feature is part of which tree in the forest, and there is no 
548 control on which data point is part of which tree. Accuracy keeps increasing as the number of

549 trees is increased but becomes constant at a certain point.

550 RFs can handle both high dimensional data and use a large number of trees where the key issue

551 is correlation reduction between the random classification variables (ability to handle thousands

552 of input variables without variable deletion) and they can be run efficiently on large databases.

553 The RF algorithm can also detect outliers, which can be very useful when some of the cases may

554 be mislabeled.

555 Random forests have been extensively applied to deltaic image classification and has resulted in 556 improved classification accuracy compared to traditional methods, such as maximum likelihood

557 (ML) and artificial neural network (ANN) methods (Adam et al., 2012; Akar and Güngör, 2015).

558 RFs outperform single decision tree algorithms (Gislason et al., 2006; Khatami et al., 2016).

559 With this combination of efficiency and accuracy, along with very useful analytical tools, the RF

560 classifier is considered very desirable for multisource classification of remote sensing and

561 geographic data. That said, RFs are not immune to caveats; they can be time-consuming, difficult

562 to construct and require greater computational resources in comparison to decision trees. In

563 addition, since RFs deal with a number of decision trees, and the randomness of features within

564 decision trees is uncontrollable, there is no way for the user to have a qualitative understanding

565 of the behavior of the dataset to have an educated guess of the outputs, and therefore, has to take

566 the output decision of the algorithm at face value. 


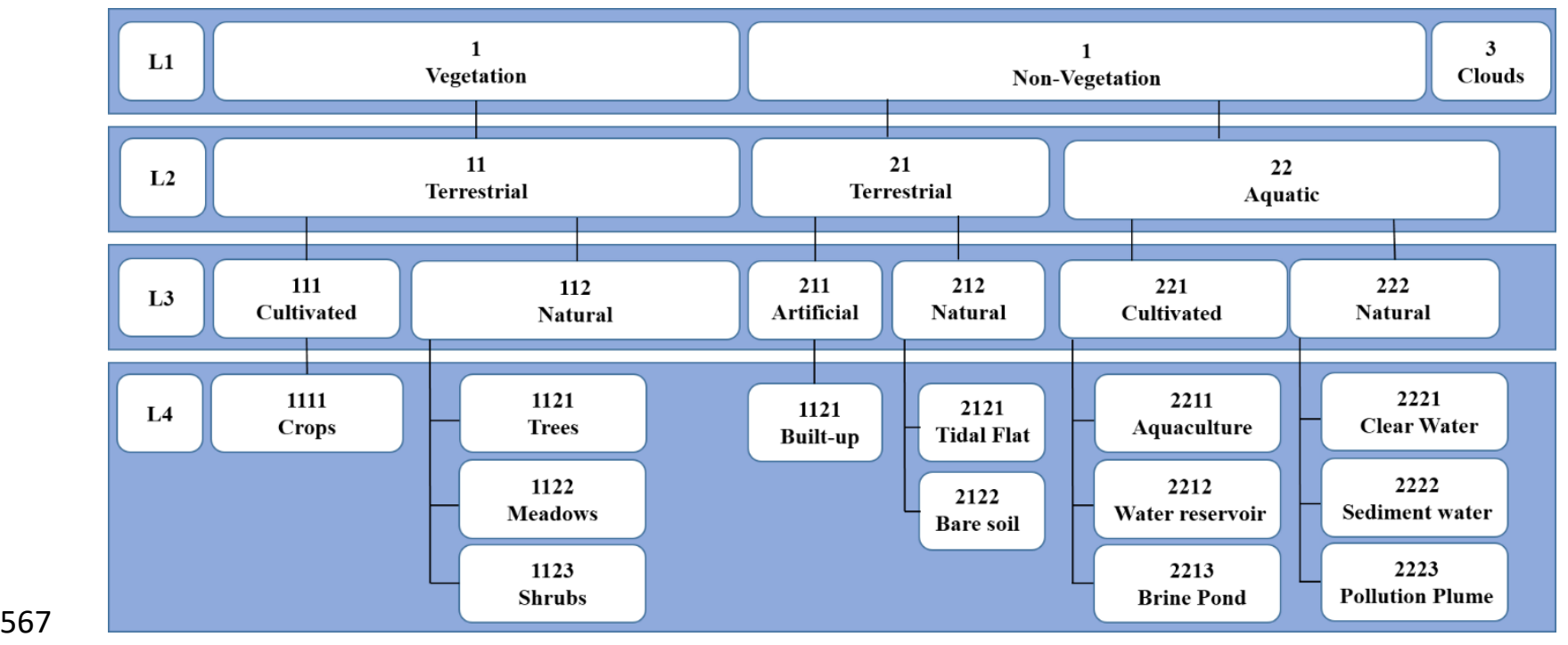

Figure 6: A decision tree to characterize different coastal features and isolate the shoreline

\subsubsection{Bayesian Networks}

Bayesian networks (BNs), also known as belief networks (or Bayes nets for short), are directed

571 acyclic graphs (DAGs) belonging to the family of graphical models (Jensen, 1996). These

572 graphical structures include nodes representing the various quantities, variables, or parameters

573 that serve as input information, and edges between the nodes (the arrows connecting the nodes)

574 representing probabilistic dependencies among the corresponding random variables. A node that

575 is not connected shows a variable that is independent by other variables represented by nodes in

576 the graph. In comparison to others, this is a relatively new method in deltaic-feature

577 identification using remotely sensed imagery. Remotely sensed imagery can be used as input

578 information (in contrast to the conventional field collected/modeled databases), and the

579 conditional dependencies in the graph are often estimated by using known statistical and

580 computational methods. The structure of a DAG in relation to evolution of a delta shoreline is

581 illustrated in Figure 7. 


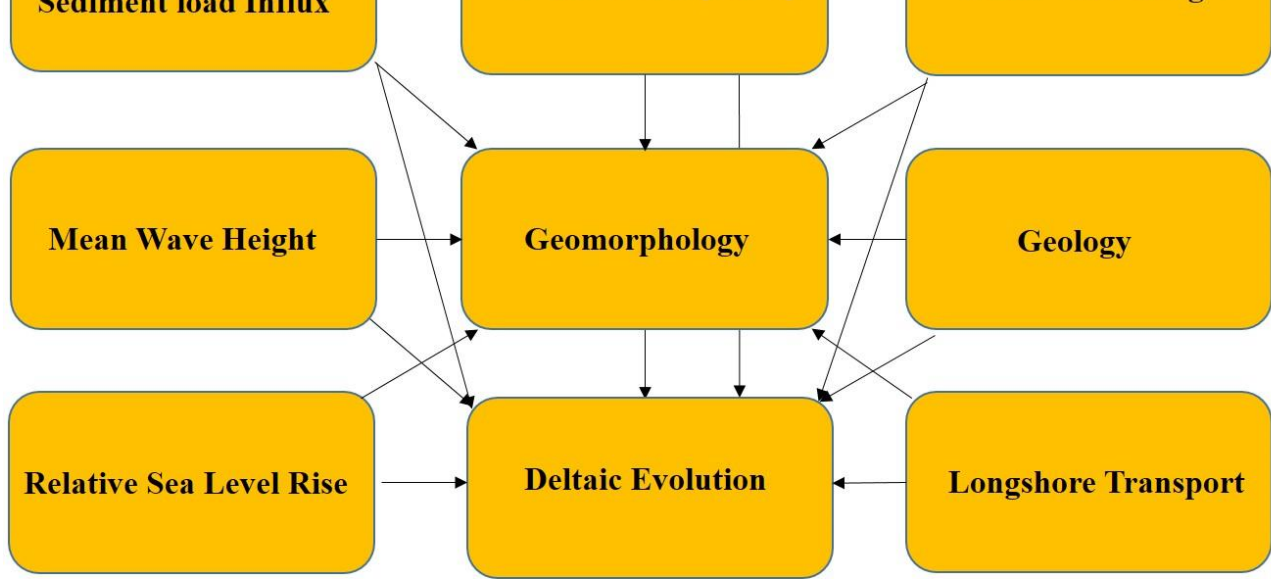

Figure 7: Bayesian Network to detect deltaic evolution. Black arrows indicate causal relationships

linking the forcing factors and the response variable (deltaic evolution)

In Figure 7, the nodes represent random variables and are drawn as boxes labeled by the variable names. The edges represent direct dependence among the variables and are drawn by arrows between nodes. In particular, an edge from node "Mean Tidal Range" to node "[Deltaic] Geomorphology" represents a statistical dependence between the corresponding variables. Thus, the arrow indicates that a value given to variable "Geomorphology" depends on the value of variable "Mean Tidal Range". Given the conditional dependencies, BNs can be effectively used to represent knowledge about an uncertain domain (e.g. "Deltaic evolution") and algorithms can

597 be created that allow for learning and inference through the use of a Bayesian network.

598 Often ANNs are compared to BNs due to their similarities in using directed graphs methods and 599 are both used as classifier algorithms in problem solving. However, unlike ANNs the BN 600 structure itself provides valuable information about conditional dependence between the 601 variables. It is a visual representation of graph that is vertices and edges have meaning in 602 comparison the ANNs where the network structure does not offer direct interpretations between 
603 nodes and can be difficult to interpret. Not many studies are found in literature which use BNs

604 exclusively for deltaic feature detection (Table 2), primarily due to the large amount of

605 supplementary data needed to setup such networks.

606

607

608

609

610

611

612

613

614

615

616

617

618

619

620

621

622

623

624

\subsubsection{Support Vector Machines}

A Support Vector Machine (SVM) is a machine-learning technique that is useful for multispectral and hyperspectral remotely-sensed classifications in which spectral separability between coastal land and water is difficult to ascertain due to lack of clear zonation between vegetation species, and mixed pixel effects. SVM differs from traditional classification approaches by identifying the boundary between classes in n-dimensional spectral-space rather than assigning points to a class based on mean values of class clusters (Heumann, 2011).

SVM creates a hyperplane through n-dimensional spectral-space that separates classes based on a user defined kernel function and parameters that are optimized using machine-learning (Figure 8). In other words, given labeled training data, the algorithm outputs an optimal hyperplane which categorizes new feature classes (Figure 8). In two-dimensional space this hyperplane is a line dividing a plane in two parts where each class lays either side of the hyperplane. By identifying the hyperplane that separates two classes rather than using the distance between class spectral means, SVM can produce a more accurate classification.

Several studies have demonstrated the great potential of SVM. Pal and Mather (2005) found that SVM outperforms maximum likelihood and artificial neural network using Landsat TM and is well suited for small training sets and high-dimensional data. Foody and Mathur (2006) found SVM outperforms discriminate analysis and decision-tree algorithms for airborne sensor data. Li et al. (2010) applied SVM to an Object-based Image Analysis (OBIA) with better results than 


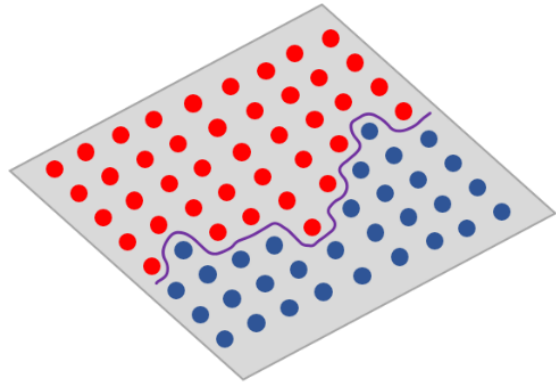

Input n-dimensional spectral space

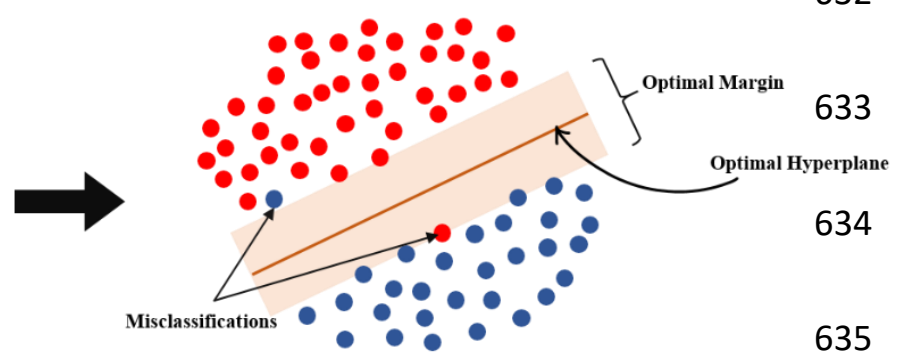

Separated Feature Space
632

633

634

635

636

\subsubsection{Object-based Image Analysis (OBIA)}

Traditional pixel-based image classification assigns a land cover class per pixel. All pixels are the same size, same shape and do not have any implicit connectivity with of their neighboring cells. OBIA, on the other hand, segments an image by grouping small pixels together into vector objects. The OBIA is a two-step process: segmentation and classification. Segmentation breaks up the image into objects representing land-based features. These segmented objects become the

644 unit of analysis, from which spectral statistics, such as spectral band means and standard deviation, or spatial information, such as image texture, can be used in the second process; image

646 classification. In image classification, according to the spectral, temporal and spatial response of 
647 land cover types in the objects, the corresponding bands and band combinations are selected, and 648 their sensitivity is trained.

649 Object Based Image Analysis is conceptually simple and generic across sensors (Blaschke, 650 2010). The key benefits of OBIA relative to pixel-based methods include: (1) the possibility to 651 incorporate user-defined scale, shape, and compactness parameters useful for creating objects 652 with heterogeneous pixels (in the process of creating objects, scale determines the occurrence or 653 absence of an object class, and the size of an object affects a classification result), in addition to 654 spectral values of the input image layers (Blaschke, 2010); (2) smoothing some of the local 655 variation within objects, which may reduce the salt-and-pepper noise and enhance classification 656 accuracy (Kamal and Phinn, 2011; Kim et al., 2011); and (3) accounting for the landscape 657 hierarchy of patch, cover type and ecosystem structure by working with multiple object layers 658 nested within each other at different spatial scales (Krause et al., 2004). The approximation of 659 ground entities and patches by image objects makes them more ecologically relevant and 660 potentially more resilient to minor geospatial positioning and image registration error than pixel 661 units (Yoshino et al., 2014).

662 Drawbacks include spectral similarity of diverse classes due to homogenizing effects of moisture 663 or dead vegetation signals, and dilution of fine morphological features which may reduce 664 classification accuracy and the effectiveness of class discrimination (Kamal and Phinn, 2011; 665 Yoshino et al., 2014). 


\section{1 (B) Sub-pixel-based methods} one land cover type within a given pixel (Figure 9), making it a challenging task to correctly

673 classify new land growth and shorefront with shoal waters.

\section{4}

Most classification approaches, as discussed above, are based on per-pixel information, in which each pixel is classified into one category and the land-cover classes are mutually exclusive.

However, in the highly turbid coastal zone, waters are mixed with various materials including suspended particles, sediments and phytoplankton, and can often be classified as "land" in many conventional algorithms. In addition, classification accuracies decrease when there is more than

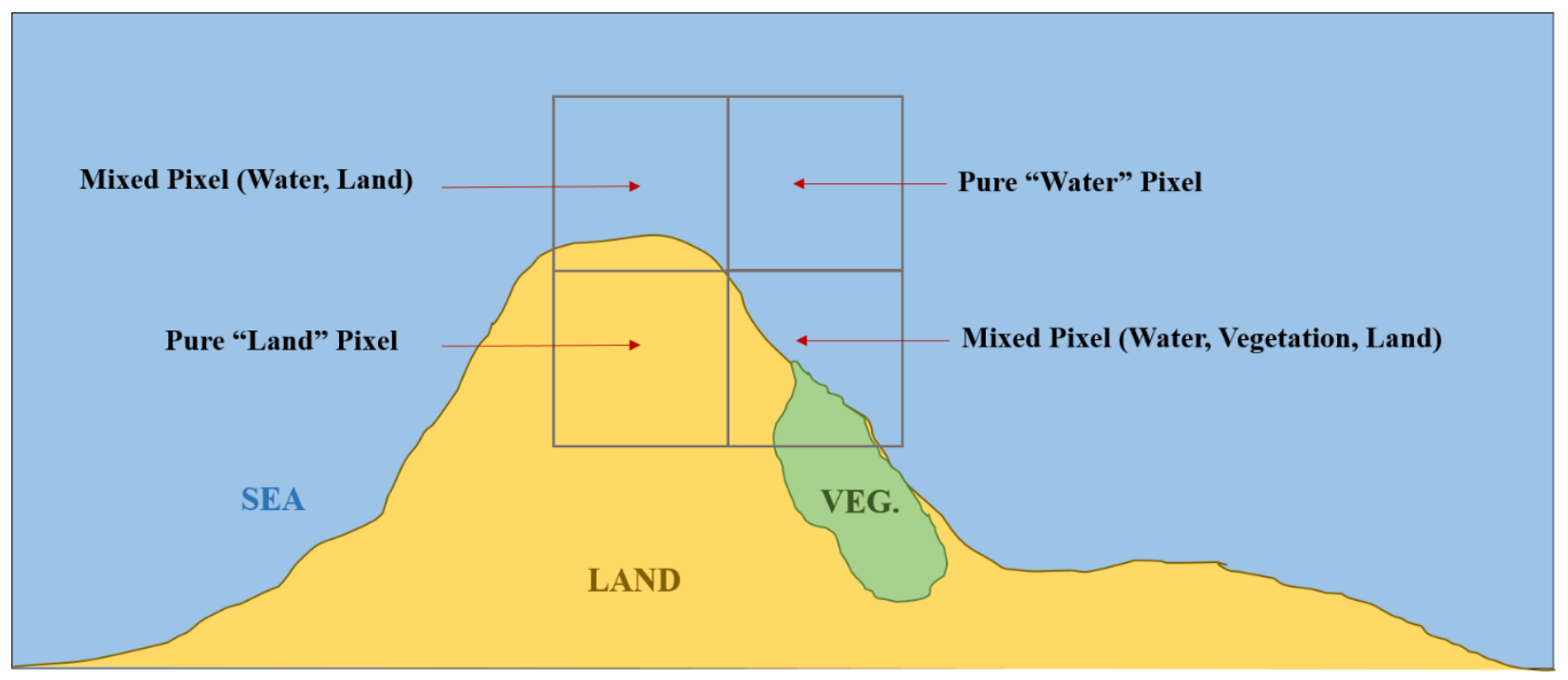

Figure 9: The case of the 'mixed pixel'

A relatively young field in image analysis, and one that has gained traction over the past decade or so, Sub-pixel representations, provide the opportunity to extract information about the fraction of different classes within a mixed pixel (soft classification). Soft Classification approaches in general were shown to result in improved cartographic representations of transitional zones and heterogeneous landscapes (Frohn et al., 2012; Wei et al., 2008; Zhang, 2009). There are three 
681 main types of soft classification approaches used in delta morphology studies currently: Fuzzy

682 Logic, Spectral Mixture Analysis, and Sub-Pixel Analysis.

\section{$683 \quad 3.1 .13$ Fuzzy Logic}

684 A fuzzy classification technique is a probability-based classification rather than a hard

685 classification. It was shown to be an extremely useful classification technique in deltaic regions

686 where the identification of the shoreline is challenging due to the shallowness and turbidity of

687 water, vegetative gradients, and dynamically changing waterline (Zhu, 2001). A fuzzy

688 classification allows a pixel to have multiple and partial class memberships to accommodate the

689 effects of mixed pixels. The conventional output of a fuzzy classification is a set of fraction

690 images which indicate the relative coverage of the classes in the area represented by the pixel. If

691 these predicted class covers could be located geographically within the area represented by the

692 pixel, it would allow the boundary between classes to be plotted at a subpixel scale.

693 Fuzzy classification has advantages over conventional methods and improves drastically on the

694 classification accuracies by fuzzy partitioning as the spectral space and retaining information

695 otherwise would have been lost due to conventional partitioning and classifier training.

696 Ghanavati et al. (2008) showed a better performance of fuzzy classification over maximum

697 likelihood classification and also showed better discrimination of mixed and unmixed land

698 use/land cover categories. It is also more feasible in integrating remotely sensed data and

699 ancillary data (Zhang \& Foody, 1998; Sha et al., 2008) such as digital elevation models, channel

700 networks and climate data (Lu and Weng, 2007). However, fuzzy classifications can be very

701 slow with long run-times during feature classifications when higher accuracies are sought after.

702 This is because additional fuzzy rules have to be incorporated into the system, and algorithms 
703 need to be tweaked (since they do not use training data) to solve for complex deltaic

704 environments.

\subsubsection{Spectral Mixture Analysis}

706 Spectral mixture analysis (SMA) enables the extraction of information about the surface

707 materials present in a pixel. This is done by calculating the least-squares best fit for each pixel

708 along mixing lines bounded by spectra of end-members and in this way accounts for each pixel's

709 variation in the mixture composition (Ozesmi and Bauer, 2002). An end-member ideally

710 represents a pure component of the mixtures present in the pixels.

711 The output of SMA is typically presented in the form of fraction images, with one image for each

712 end-member spectrum, representing the area proportions of the end-members within the pixel.

713 End-member selection is one of the most important aspects in SMA, and much previous research

714 has explored selection/identification approaches (Mustard and Sunshine, 1999; Theseira et al.,

715 2003; Small, 2004).

716 Previous research has demonstrated that SMA is helpful for improving classification accuracy

717 (Shimabukuro et al., 1998; Lu et al., 2003) and is especially important for improving area

718 estimation of land-cover classes based on coarse spatial resolution data. Albeit its increased

719 accuracy over other methods, SMA suffers from two major caveats of 1) not having potential

720 end-members occurring in patches larger than the image resolution; there could exist earth

721 features in smaller patches smaller than pixel dimensions. This makes the identification of an

722 end-member for classification impossible and consequently be classified erroneously. 2) end-

723 members not being truly constant within an image; there always exist a range of reflectance

724 values for a particular end-member class that could result in overlap between different end- 
725 member classes. This could create a mismatch between the defined end-member and ground 726 truth and yield misclassification results.

\section{$727 \quad 3.1 .15$ Sub-Pixel Analysis}

728 Sub-pixel processing is defined as the search for specific materials of interest from within a

729 pixel's mixed multispectral image digital number spectrum. This method has advantages over

730 SMA and fuzzy classifications, because the overall composition of each pixel is not limited to a

731 combination of already defined image classes (end-members). The steps in sub-pixel processing

732 include signature derivation for a material of interest and classification of each pixel identifying

733 the fraction of material of interest present. Therefore, for each material a separate classification

734 must be done. The fraction image pixel values vary from 0.0 to 1.0 (Ozesmi and Bauer, 2002).

735 This specific technique of sub-pixel analysis in deltaic environments was the least used

736 technique in the reviewed literature.

\section{3.1.16 General Concerns about Techniques used in Two-Step Change Detection}

738 The 15 techniques used in Two-Step Change Detection for delta morphology analysis described

739 above, although commonly used, share some inherent limitations. One limitation is that since

740 separate classifications are carried out on two different satellite images before detecting the

741 deltaic change, the accuracy of the change map typically will be at best the multiplication of the

742 accuracies of each individual classification for each date (Serra et al., 2003). This is a concerning

743 problem as this error can be significant at times, especially when multiple time steps are

744 compared. Also, when the analyses include utilization of imagery from longer archives (i.e. use

745 of different Satellites even in the same constellation; e.g. Landsat MSS, TM etc.), it is inevitable

746 that different data extraction and classification algorithms needed to be used to infer deltaic 
747 features (due to the variability of spectral resolution of bands). This process, in addition to the

748 caveat mentioned above, carries the distinct disadvantage of having uncertainties occurring due

749 to differing classification/extraction algorithms. Thus, the two-step detection will incur an

750 additional step of quantifying of uncertainties.

751 Furthermore, Two-Step Change Detection, since it requires the production of at least two

752 different maps, can be operationally complex and computationally intensive (especially on high

753 resolution multispectral imagery covering large areas). Therefore, the use of said methods to

754 produce time series of change-maps can be difficult and expensive. Multi-temporal image

755 comparison techniques/One-step change detection techniques (discussed below) were, in part,

756 developed to alleviate these limitations.

\section{$757 \quad 3.2 \quad$ Classification Techniques used in One-Step Change Detection}

\subsubsection{Image Differencing/Layer Arithmetic}

759 In this technique, spatially registered images from different times are subtracted, pixel by pixel, 760 to produce a layer which represents the change between the two. This procedure yields a 761 difference distribution for each band (i.e. a histogram). In such a distribution, pixels of small

762 radiance change are distributed around the mean, while pixels of large radiance change are

763 distributed in the tails of the distribution (Mas, 1999). A critical element of the image

764 differencing method is deciding where to place the threshold boundaries between change and no765 change pixels displayed in this distribution.

766 Although Image Differencing is a widely used technique for change detection and has been used

767 in river deltas of different geographical environments (Table 2), interpreting the difference image

768 can be difficult because different input values can have similar output results after subtraction 
769 (e.g. input pixel values of 190 and 150 can have the same result of 40, as inputs of 100 and 60,

770 after subtraction), and also since the original pixel value information is not retained for further

771 investigations (Cohen et al., 1998). The mathematics of typical image differencing is shown in

772 Figure 10 below.

Time Step 2

\begin{tabular}{|c|c|c|c|}
\hline 142 & 136 & 134 & 145 \\
\hline 175 & 181 & 186 & 188 \\
\hline 180 & 195 & 198 & 210 \\
\hline 140 & 148 & 152 & 156 \\
\hline
\end{tabular}

Time Step 1

\begin{tabular}{|l|l|l|l|}
\hline 150 & 145 & 130 & 141 \\
\hline 180 & 185 & 191 & 185 \\
\hline 159 & 160 & 208 & 215 \\
\hline 168 & 175 & 185 & 180 \\
\hline
\end{tabular}

Difference Image

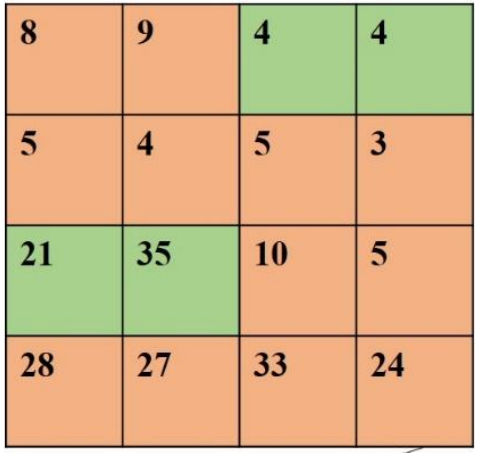

773

774

775

776

777

778

779

780

781

782

Figure 10: Image differencing workflow between typical rasters. The values are arbitrary values used for illustration purposes.

\subsubsection{Change Vector Analysis}

Change Vector Analysis (CVA) is an enhanced version of band differencing. It detects changes above a selected threshold value to generate a binary image of change and no-change pixels (Singh and Talwar, 2013). A change vector can be described as an angle (vector direction) and a magnitude of change between two different time instances from multi-spectral satellite data (Civco et al., 2002). A decision on change is made based on whether the change magnitude exceeds a specific threshold. Once a pixel is identified as changed, the direction can be examined further to determine the type of change. The type of change is often identified using the angle of 
783 the vector in two spectral dimensions (Chen et al., 2003). Although initially developed for only

784 two spectral bands, modifications to CVA enable its use to any number of spectral bands

785 (Bayarjargal et al., 2006).

786 In addition to providing the direction of change, which is unparalleled to other techniques

787 discussed, CVA also has the capability of avoiding cumulative error in image classification of an

788 individual date and processing any number of spectral bands simultaneously to retrieve

789 maximum "from-to" type information. However, like other radiometric change approaches, CVA

790 also has several drawbacks that limit its use. These include a strict requirement for reliable image

791 radiometry. CVA is based on pixel-wise radiometric comparison and so the accuracy of image

792 radiometric correction (for alleviating the impacts caused by disturbing factors such as different

793 atmospheric conditions, solar angle, soil moisture and vegetation phenology, etc.) is more critical

794 for CVA than for spectral classification approaches. Another drawback is a lack of automatic or

795 semiautomatic methods to effectively determine the threshold of change magnitude between

796 change and no-change pixels (Chen et al., 2003).

\section{$797 \quad 3.3 \quad$ Ensemble Classifications}

798 Different image classification methods, such as parametric classifiers (e.g. maximum likelihood)

799 and non-parametric classifiers (e.g. neural networks, decision trees), have their own strengths

800 and limitations (Tso and Mather, 2001). For example, when sufficient training samples are

801 available and the features in a dataset are normally distributed (distribution in space; among

802 pixels), a maximum likelihood classifier (MLC) may yield an accurate classification result. In

803 contrast, when image data are anomalously distributed, neural network and decision tree

804 classifiers may demonstrate a better classification result (Lu et al., 2004). 
Ensemble (Hybrid) classification methods combine the strengths of multiple classification approaches. They can be valuable for river delta studies because of how they effectively address the complex variability in spectral responses of shoreline environments. Ensemble classifications can be classified into two approaches: 1) classifying a single image of a particular time step and then comparing it with an image of a different time step (classified using the same techniques or otherwise), or 2) directly comparing between two timestamps. The direct comparison between time steps is often expressed as a layer arithmetic operation to identify changed elements (locating change through e.g. CVA), followed by a supervised or unsupervised direct classification of the changed features (Lu et al., 2004). Previous research has indicated that the integration of two or more classifiers provides improved classification accuracy compared to the use of a single classifier (Warrender and Augusteihn, 1999; Steele, 2000; Huang and Lees, 2004; Khatami et al., 2016). In an effort to not duplicate studies and maintain the succinctness of the document, the readership is reverted to sections discussed above $(3.1 .1-3.1 .15 ; 3.2 .1$ and 3.2.2) where instances of ensemble classifications can also be found. A note of caution when applying ensemble classifications is that the uncertainties occurring from different techniques have to be quantified and factored into accuracy calculations of feature extractions, as they can be significant depending on the methods used and the number of time steps of satellite imagery processed.

As evident from the discussion in sections 3.1-3.3, sub-pixel-based classifications tend to yield better results than pixel-based classifications. However, sub-pixel-based methods can be computationally expensive, and algorithm development can be time consuming. Thus, the choice of a sub-pixel-based algorithm is a trade-off between how complex the deltaic environment is, how big the river delta is (i.e. is the value of a pixel significant in comparison to the size of the 
828 delta?), and what is the time span of the delta change analysis (are multiple image time steps

829 involved which could compound uncertainties). In addition, since there is also the problem of

830 compounding error resulting from classification techniques of different time steps, development

831 of algorithms to detect sub-pixel heterogeneity can be worthwhile if a one-step change detection

832 method, even pixel-based (e.g. image differencing. CVA), can achieve comparable results as

833 sub-pixel algorithms.

\section{$834 \quad$ 4. Other Delta Morphology Change Indicators}

835 Section 3 of the manuscript focused on one delta morphology change indicator: the shoreline.

836 The discussion of all other environmental indicators in one section is due to that fact that the

837 number of studies pertaining to every other environmental indicator was markedly less than

838 those for deltaic shoreline change studies. We attribute this to two reasons 1) research interest:

839 more attention is given to how deltaic landmass available for humans evolve over time (governed

840 by the shoreline), and 2) methodological challenges: difficulty for classification algorithms to

841 distinguish between spectral characteristics of these specific deltaic features and the surrounding

842 terrain features. The shoreline, on the other hand, even with its own complexities at the land-sea

843 margin, is relatively easier to detect, as changes in spectral characteristic between land and sea

844 are comparatively prominent. Possible pathways to address these less-researched environmental

845 indicators are discussed as future directions in section 5. The following sub-sections will discuss

846 studies with regard to other deltaic morphology change indicators. The importance and role of

847 these indicators in delta morphology change detection is summarized in Table 1. 


\subsection{Meander Belts}

849 Lateral migration as a response to variations in river flow and sediment discharges is associated with erosion of the stream bed or channel bank and can cause many geomorphological and river management problems on a delta (Le et al., 2006). Mathers and Zalasiewicz (1999) used a combination of filtration and contrast stretching on Landsat TM imagery to map and classify Meander Belts of the Red River in the Red River Delta in Vietnam. Yang (1996) and Yang et al. (1999) used Manual Digitization and Band Ratioing/Manual digitization on Landsat MSS and TM imagery to identify channel shifting change (Channel Migrations), channel geometric change 856 (Channel length and width) and channel pattern change (braiding, straight, slight meandering) of the Yellow River in the Yellow River Delta. Seker et al. (2005) studied meander migrations of the Filyos River in and upstream of the Filyos delta, Turkey (Figure 11) and Ghanavati et al.

859 (2007) used topographic maps and Landsat TM and ETM+ imagery to detect channel migrations 860 in the Hendijan River delta, Iran.

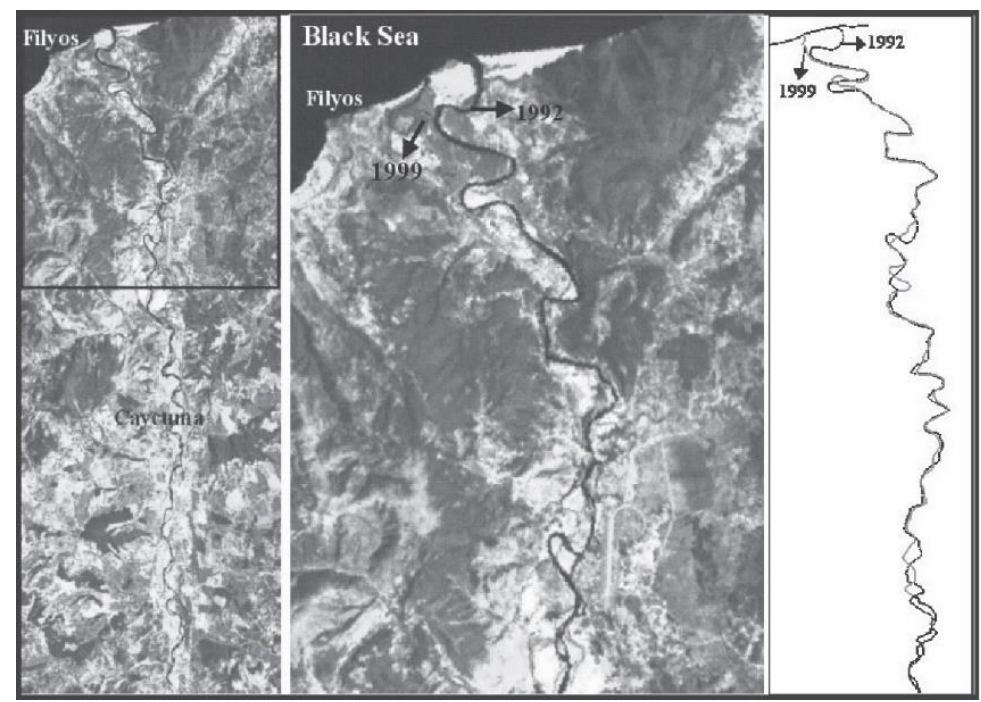

Figure 11: The meandering of the Filyos River through time observed using satellite imagery. 


\subsection{Crevasse Splays, Channel Avulsions and Distributary Networks}

870

871

872

873

874

875

876

877

878

879

880

881

882

883

884

885

886

887

888

Syvitski et al. (2012) used SRTM (Shuttle Radar Topography Mission) interferometric synthetic aperture radar (InSAR) data to study zones of nodal avulsions in 33 lowland floodplains (inclusive of deltas). Li et al. (2014) used Landsat MSS and TM imagery, and Li and Bristow (2015) used QuickBird-2 and WorldView-2 imagery to monitor flood-induced river morphology changes and to study splay development morphology respectively in the Río Colorado river delta in Salar de Uyuni, Bolivia (Figure 12). Mathers and Zalasiewicz (1999) used Landsat TM with the integration of geological data to study tidal creeks, channels, anastomosing rivers in the Red River Delta, Vietnam. Isikdogan et al. (2015) proposed an algorithm to automatically extract the channel networks from satellite imagery where water and non-water pixels have the greatest spectral contrast, and in an innovative use of high resolution google earth imagery, Gugliotta et al. (2019) obtained channel network widths and sinuosity of five deltas (Fly, Yangtze, GBM, Irrawaddy, and Mekong).

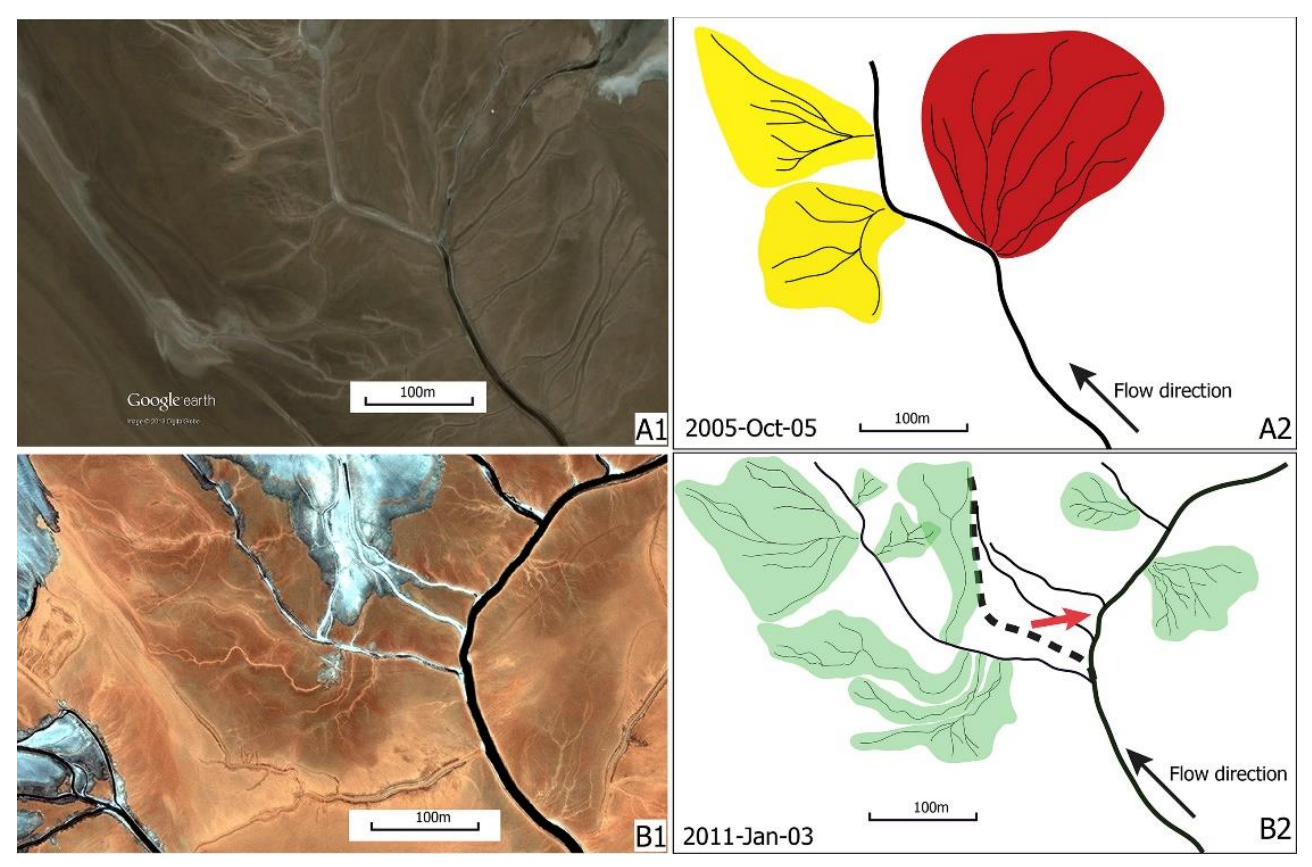


Figure 12: Crevasse splay-led avulsion in the Salar de Uyuni, Bolivia. A1 and B1: The same region observed from Quickbird (A1) and Worldview-2 (B1) satellites at two different times; A2 and B2: Line drawings, main river channel is demarcated by the thick black line. A2: yellow splays represent Inactive Crevasse Splays; red splay demarcates the site where avulsion occurs. B2: green splays represent new crevasse splays. Dashed line indicates river channel before avulsion. The arrow shows the channel shift after avulsion. Source: Li and Bristow (2015).

Studies of splays, avulsions and channel networks is particularly challenging in coastal deltas

896 due to low topographic gradients, the presence of features such as sediment plumes, and the wide 897 range of scales over which channel features are present. Channel networks identified in most of 898 the studies were as good as the moderate resolution of the satellite imagery used. In addition, robust channel extraction methods would ease monitoring coastal areas and analyzing deltaic response to anthropogenic and natural forcing over large spatial areas and long temporal intervals. The role of higher resolution satellite imagery in better identifying these deltaic features and the need for more robust deltaic feature extraction methods based on these better 903 platforms is discussed in section 7.

\subsection{Barrier Islands, Beach Spits, and Mouth Bars}

905 Frihy et al. (1998) used Landsat satellite data to assess the evolution of the coastal spit and 906 changes in the lagoon margin and contiguous barrier islands in the Damietta Promontary of the 907 Nile River Delta. Nandi et al. (2016) used Tasseled Cap Transformation on Landsat MSS, TM, 908 ETM+ while Gopinath and Seralathan (2005) used image differencing on satellite data of the 909 Indian Remote Sensing Satellite-IC to monitor changes of Sagar Island, the largest mouth bar of 910 the Ganga-Brahmaputra-Meghna (GBM) delta. Demers et al. (2015) used RADARSAT-2 C-

911 band and optical satellite data to map the shoreline of islands of the outer Mackenzie Delta using 
912 Object Based Image Analysis. A common problematic are highlighted in these studies was

913 detecting these morphological features using medium to coarse resolution imagery. Better pixel

914 resolutions in comparison to the scale of deltaic features (Figure 13) were shown to be an area of

915 improvement for better feature detection. In addition, the detections were heavily impaired by

916 the sediment plume in the delta nearshore environment. The necessity of data mining and sub-

917 pixel analyses was apparent. We discuss these shortcomings and possible pathways forward in 918 detail in section 7; Future Directions.
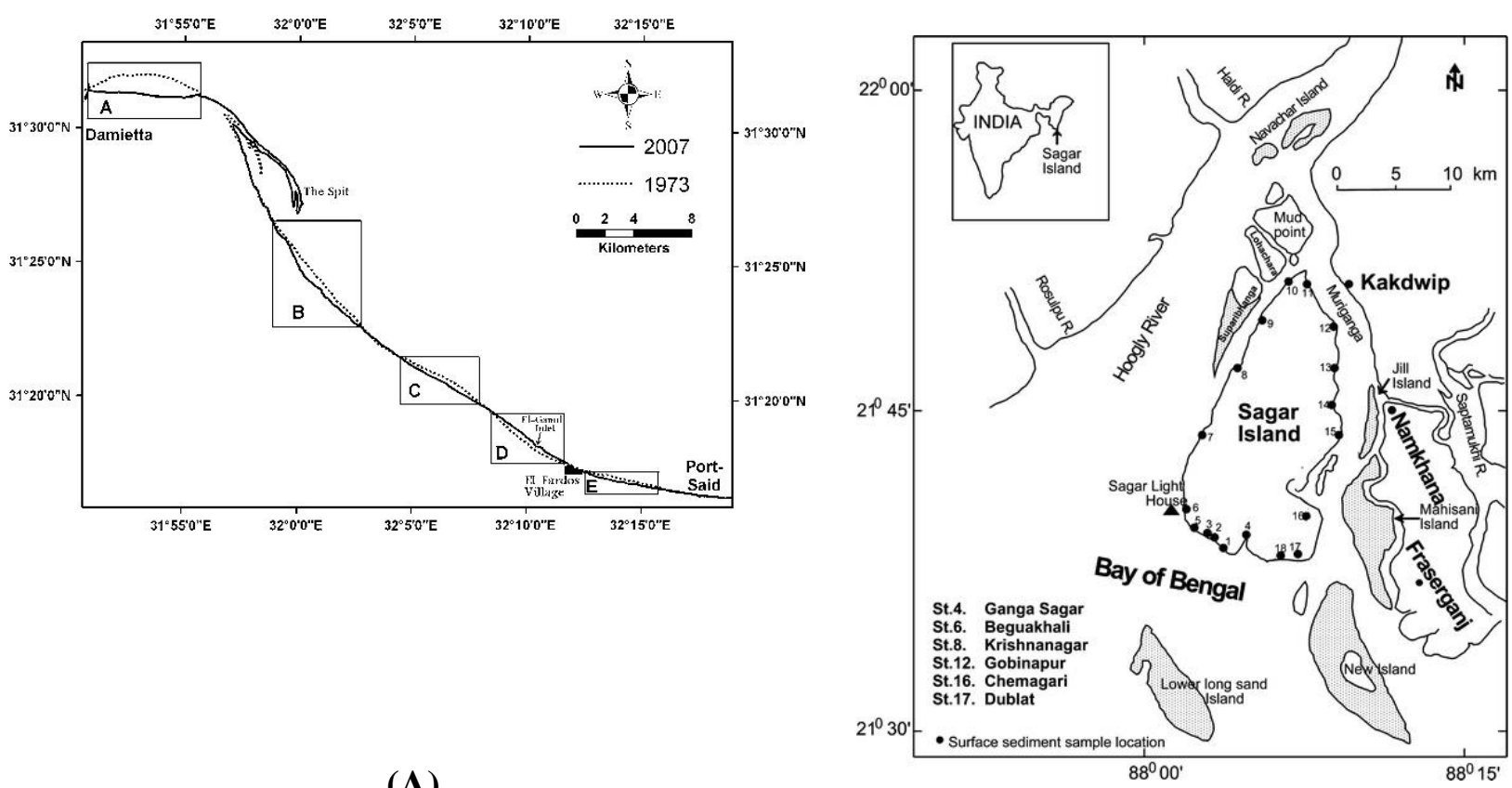

Figure 13: (A) The shoreline position change through time (1973 and 2007) between Damietta and Port-Said of the Nile River Delta. A prominent beach spit is visible between locations A and B. Source: El-Asmar and Hereher (2011). (B) Location of The Sagar Island, the largest barrier Island

927 in the Ganges-Brahmaputra-Meghna Delta. Ground control points were collected at each sampling 928 station to calibrate satellite data. Source: Gopinath and Seralathan (2005). 


\section{Synthesis and Applications}

\section{$930 \quad 5.1 \quad$ Machine Learning}

931 One of the major insights stemming from this literature review is that sub-pixel-based methods

932 tend to yield the highest accuracies among all the discussed methods in morphology change

933 detection, while machine learning (ML) techniques perform relatively better (contingent upon

934 good training data, and knowledge and skill of the algorithm developer) than conventional pixel-

935 based techniques (band ratioing, density slicing). The former is a straightforward conclusion

936 given that sub-pixel-based methods inspect details within the constraints of a pixel to elucidate

937 information about the land surface which is otherwise impossible through pixel-based methods;

938 higher level of inspection within a pixel will yield greater amounts of detail.

939 Perhaps more interesting is the insight that ML techniques (e.g. ANNs, Bayesian networks etc.)

940 perform better than conventional methods, given that they both work at a pixel-level. It is also

941 found that using a combination of ML techniques with others (another ML technique or other

942 conventional ones) was shown to yield very high accuracy and utility in morphological feature

943 classification. Thus, it is worthwhile examining why ML techniques perform well in deltaic

944 environments, so we could better understand and harness their strengths to developing data

945 mining algorithms in under-studied deltaic regions of the world, and even solve image

946 classification issues in other sub-disciplines of satellite remote sensing.

947 The reasons for the success of ML techniques in case studies in the studied literature lie in the

948 complexity of the deltaic system itself. One of the fundamental characteristics of a complex

949 system is that classification results are non-linear stemming from the heterogeneity in the system

950 (a spectral reflectance of $x$ denoting water at one location, might be a mixture of mud, water and 
951 vegetation debris, at another). A conventional algorithm is designed to classify the system using

952 a simple succession of steps subject to simple conditions. ML algorithms, on the other hand,

953 have the ability to identify complex relationships through the testing of a very large number of

954 possibilities. Typically, the algorithm runs multiple experiments of classification on the primary

955 image data before arriving at a final decision output. The outcome of the second experiment will

956 not be the same as the first, and the final result is thus an ensemble of the two. ML algorithms

957 work on the principle that it generally approximates the truth instead of aiming to find it exactly,

958 in comparison to conventional methods, which in a complex domain such as a delta, can lead to

959 lowered accuracies due to misclassification. The approximation of the truth of ML techniques,

960 thus, also provide a measure of uncertainty, and can act as platforms for other types of research

961 to build up on, which can later-on be incorporated into the decision-making process. Secondly, in

962 a ML algorithm, many other factors related to morphology change are considered before

963 assigning a label to a particular image pixel (e.g. see Figure 7 of how a Bayesian network solves

964 for a deltaic evolution). This provides ancillary data (remotely sensed or not) of the deltaic

965 environment, which improves the classification accuracy of the algorithm.

966 We understand that not every researcher engaged in remote sensing possesses the skills of

967 developing complex ML algorithms. Therefore, we would also like to make a point that although

968 ML algorithms are favorable, a combination of conventional methods in an ensemble could also

969 lead to good classification accuracies. 
970 What type of algorithm should one use for delta morphology detection? Is it worth the effort of

971 going the entire distance of developing highly accurate, complex ML algorithms when,

972 comparable results can be achieved through already existing conventional remote sensing

973 techniques? The answer to these questions, in our opinion, depends on several factors. The most

974 important is the study domain of interest. For example, the Damietta and Rosetta Promontaries of

975 the Nile River Delta, Egypt (which are made of the Damietta and Rosetta branches of the Nile

976 River, respectively) are cuspate shaped, with straight forward land-sea margins (Figure 14a).

977 Due to the clear difference in spectral signatures the deltaic land can be clearly distinguishable

978 from the ocean. On the contrary, the Ganges-Brahmaputra-Meghna (GBM) delta in

979 India/Bangladesh has intricate coastal features on the land-sea margin (Figure 14b). The

980 extensive anastomosis of channels, huge volume of sediment output, complex vegetation

981 gradient, presence of barrier islands, mouth bars and lagoons at the land-sea interface

982 complicates the detection of morphological features.

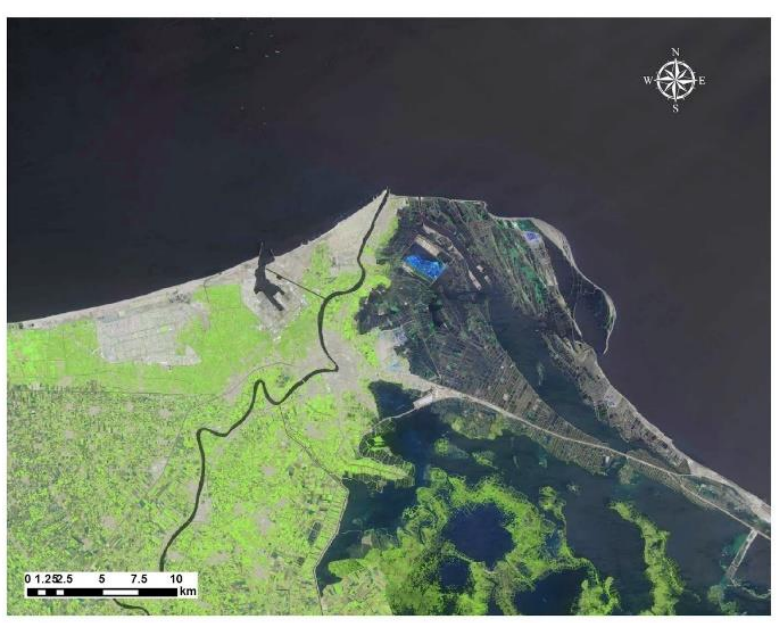

(a)

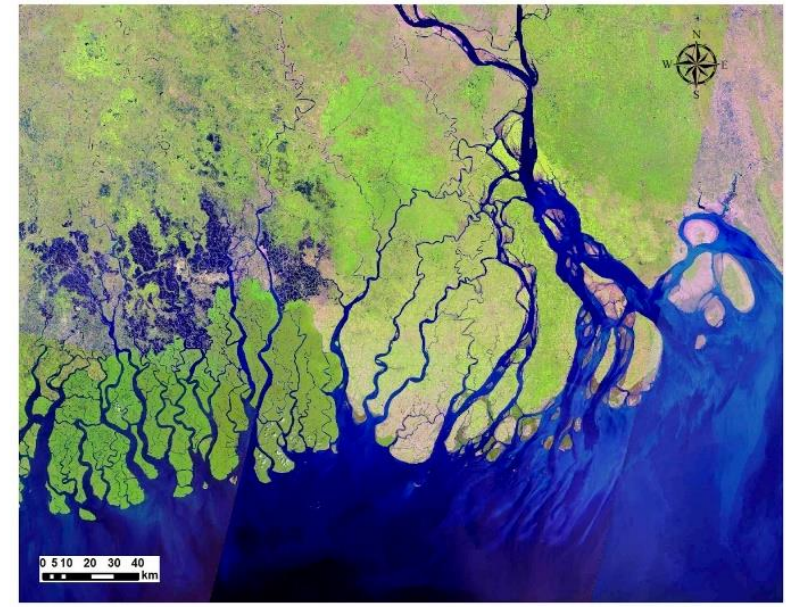

(b) 
985 Therefore, it would be prudent to use a combination of conventional techniques to monitor the 986 Nile, in order to utilize available resources (time, user-skills) effectively rather than going the 987 extra step of deep algorithm development, which might be very well the case for the GBM delta.

988 It is therefore of utmost importance to have an understanding of the complexity of the study 989 domains prior to the development of research methodology. It is also important to be informed 990 how of data-intensive and computationally costly these algorithms are. For example, a Bayesian 991 network might be significantly better than a simple band ratio, but is it worth the trade-off of 992 time that one would invest to develop the algorithm and the amount of ancillary data (which 993 might need to be purchased and pre-conditioned) that is required to arrive at a relatively 994 uncomplicated feature extraction?

\section{$995 \quad 5.2 \quad$ Radar Imagery}

996 Literature about the use of Radar imagery for deltaic morphological feature detection was 997 minimal compared to optical platforms. This is likely due to a combination of factors. The first is 998 the premium access that was needed for almost all radar archives until very recently. Research 999 proposals on intended projects had to be submitted to data providing agencies, and on most 1000 occasions, imagery had to be purchased. Secondly, unlike the lengthy activation periods of 1001 optical platforms (e.g. Landsat, since 1972) the discontinuation of radar platforms within a short

1002 period of time has led to short archival length of radar imagery which consequently resulted in 1003 difficulty in monitoring deltaic changes over time. Thirdly, skilled photogrammetric operators 1004 are needed to process and analyze radar imagery, and these skills are not ubiquitous. Fourthly, 1005 and most importantly is the utility in distinguishing on-land deltaic features such as crevasse 1006 splays and avulsions, especially in complex deltaic regions. Although radar imagery is well 1007 utilized in shoreline delineation (see examples in Table 2), there is no conclusive evidence that 
suggests that Radar imagery performs well in comparison to optical imagery in recognizing onland deltaic features. Thus, given the choice between optical and radar platforms, the rational selection seemed to be optical imagery over the years in most cases. However, with open accessibility policies to radar archives through the Copernicus Program of the European Union, Alaska Satellite Facility and the Japan Aerospace Exploration Agency (JAXA), and training programs/Webinars offered by NASA, European Space Agency and other private institutions, opportunities in relation to feature detection are expected to open into the future.

\section{Intercomparison of Delta Morphology Feature Extraction Techniques}

One of the more important insights that we draw from the summation of studies is that the review of literature revealed no clear clustering of a particular set of technique(s) that could be used for feature extraction for a particular type of delta (e.g. river-dominated vs. tide-dominated). One or two given techniques which were used to extract a particular morphological feature (e.g. shoreline) of a particular type of delta (e.g. river-dominated delta) was not necessarily ideal for a river dominated delta elsewhere on the earth. This is understandable as deltaic morphology dynamics are driven by many other location/climate related factors (e.g. inherent variability in rainfall, soil minerals, growing cycle phases of vegetation) that make the identification of morphological features even using the same technique complex. We noted that there were not enough comparison studies which 1) compared multiple techniques at a given case study, nor 2) comparisons of even one or two techniques across multiple case studies in different geographical regions of the world. The notion of which technique(s) would be the most appropriate for a given deltaic region would be immensely important for potential future research as these could be used to infer on how to fine tune algorithms to compensate for environmental noise, and subsequently 
1030 accurately detect deltaic landmass evolution over time. This will help us infer why particular

1031 techniques underperform in differentiating earth features in different geographic regions of the

1032 world, enabling deeper investigation into some of the inherent problems of particular techniques

1033 and provide a platform for their improvement. In addressing this niche, we evaluated 7

1034 techniques on 10 different river deltas (Amazon, Chao Phraya, Burdekin, Brahmani, Po, Danube,

1035 Ebro, Han, Irrawaddy, Colorado) globally, belonging to different river delta types (i.e. river-

1036 dominated, tide-dominated, wave-dominated) and representing the different Köppen climate

1037 classes.

1038 Five conventional and two ML methods were compared. The conventional methods are: 1)

1039 Modified Normalized Difference Water Index (MNDWI), 2) Normalized Difference Water

1040 Index (NDWI), 3) PCA analysis, 4) Unsupervised Classification, and 5) Supervised

1041 Classification)]. The ML techniques used are: 6) Random Forest Classifier, and 7) Support

1042 Vector Machine)]. These seven techniques were selected as they were the most used as per our

1043 review. All were compared against hand-digitized vectors (used as a reference baseline) of

1044 Landsat-OLI 2018 imagery for the 10 case study deltas (the number of case studies were

1045 constrained by the availability of sufficient training data for ML techniques). The accuracy of

1046 different indicators of morphology (shoreline, beach spits, mouth bars etc.) were evaluated

1047 against the hand-digitizations based on two parameters: a) the continuity of the technique-

1048 derived vector to the reference baseline, and b) Proximity of technique-derived vector to the

1049 reference baseline. A new robustness index $(R)$ was developed which joins both metrices:

$1050 R=\frac{L_{E} * 100 / L_{R}}{D_{E A}}$ 
where $L_{E}$ is the length of the extracted shoreline, $L_{R}$ is the length of the real shoreline, and $D_{E A}$ is the averaged perpendicular distance between the extracted and real shoreline. The $R$ index value increases as the shoreline extracted by a given method is closer to the real shoreline in length, whereas robustness decreases as the extracted shoreline is farther away from the real shoreline. Best and worst performing techniques of each delta are summarized in Figure 15 below.

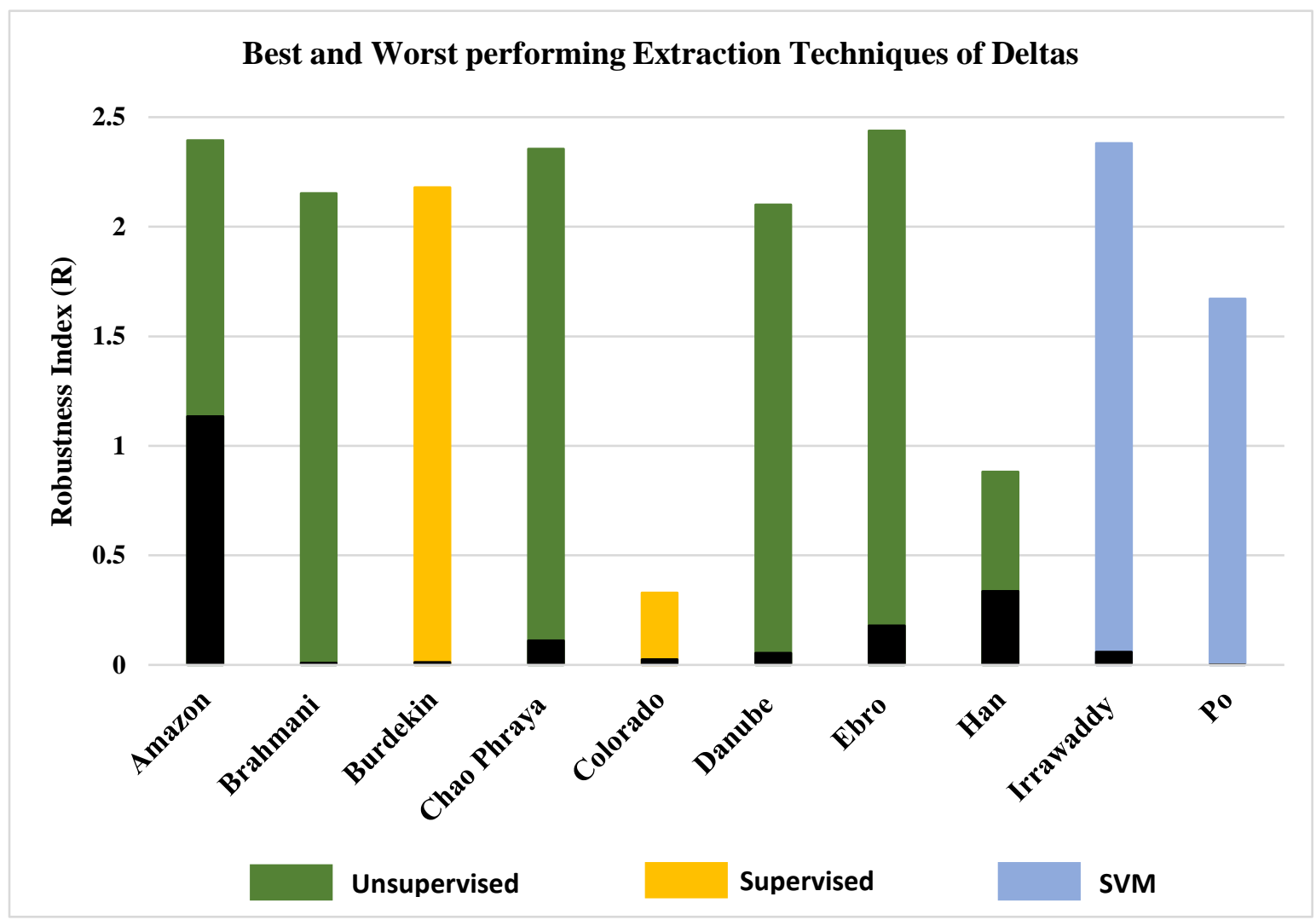

Figure 15: A summary of the best and worst performing techniques of the sample deltas.

Supervised Classifications performed the best across all morphology indicators (e.g. beach spits, tombolos, shoreline) (Figure 16). For the Po and Irrawaddy Deltas, the Support Vector Machine algorithm performed the best. PCA ranked the lowest among the techniques for all the deltas, and we attribute these low PCA scores to the non-capture of boundary line land-sea pixels as 1063 'noise', from the first few principal components during the transformation process. 

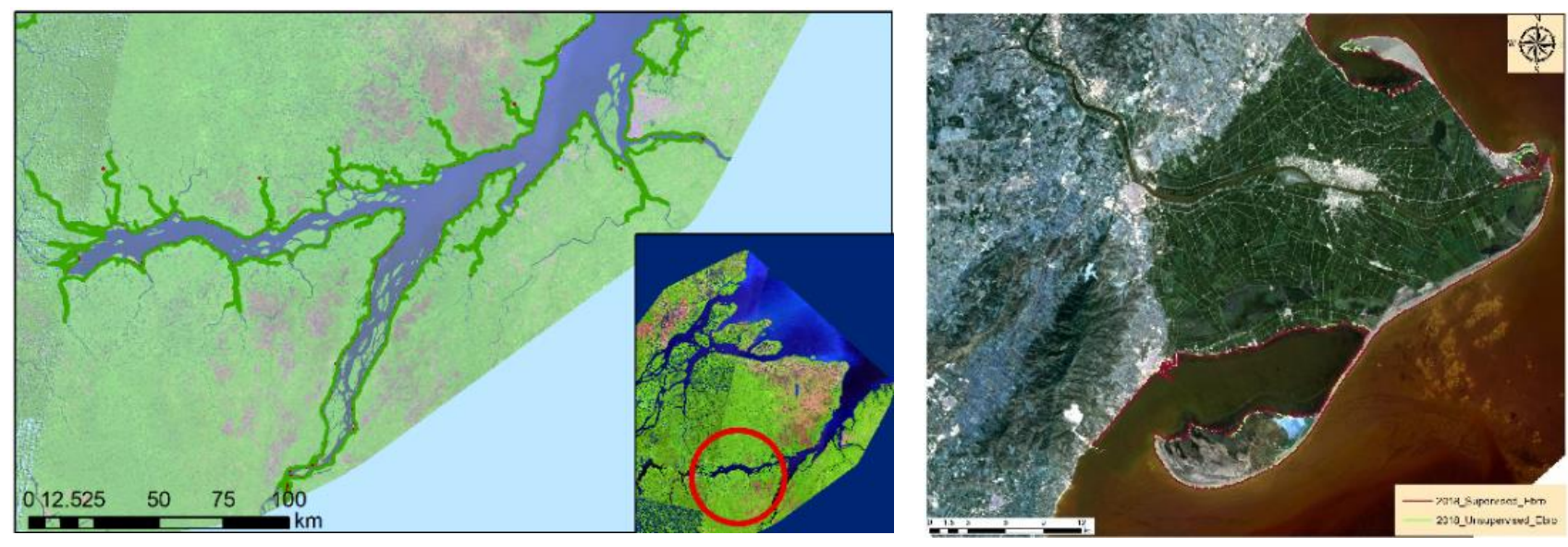

Figure 16: Algorithm performance on delta morphology indicators. left: the detailed extraction of extensive channel networks of the Amazon river subsequent to unsupervised classification. Right: A comparison of vectors of shoreline and beach spit extractions between unsupervised (green) and supervised (red) of the Ebro delta.

However, when the performance of all the techniques were summarized (Table 1) and analyzed for robustness, we find that Unsupervised Classification yielded the best performance on average. A nonparametric ANOVA showed that when all river deltas were considered,

1072 Robustness $(R)$ values of Unsupervised Classifications were significantly outperforming all the 1073 other techniques. SVM, Supervised Classifications, and Random Forest Classifications did not 1074 show a significant difference $(\alpha=0.05)$ between each other. The two ratioing techniques' 1075 performance also did not have a significant difference between each other $(\mathrm{P}=0.79 ; \alpha=0.05)$. All 1076 other techniques had significant differences with PCA (Table 1).

1077 Table 3: The ranges of the percentage lengths of extracted shorelines, their average distances from 1078 the real shoreline and mean robustness values for each technique, for the entire suit of deltas (10) 1079 analyzed. 


\begin{tabular}{|l|l|l|l|}
\hline Technique & $\begin{array}{l}\text { Range of } L_{E}(\%) \text { (Median in } \\
\text { parenthesis) }\end{array}$ & $\begin{array}{l}\text { Range of } D_{E A}(m) \\
\text { (Median in parenthesis) }\end{array}$ & $R$ mean \\
\hline Unsupervised & $78-100(98)$ & $40-239(45)$ & 1.72 \\
\hline SVM & $36-99(79)$ & $42-340(60)$ & 1.17 \\
\hline Supervised & $56-99(87)$ & $45-246(87)$ & 1.14 \\
\hline Random Forest & $45-97(76)$ & $45-471(78)$ & 0.95 \\
\hline MNDWI & $23-79(50)$ & $78-587(229)$ & 0.32 \\
\hline NDVI & $29-70(52)$ & $105-623(172)$ & 0.31 \\
\hline PCA & $4-84(24)$ & $75-2668(427)$ & 0.19 \\
\hline
\end{tabular}

We did not observe clustering of techniques around delta types, nor between deltas in specific Köppen climate classes. However, it must be noted that these are only a small sample of deltas from each delta type and Köppen category. It was interesting to note how although past literature showed that support vector machines (SVMs) as the best among pixel-based classifications, our comparisons yield mixed outcomes (SVM performing best in only 2 cases out of the 10, and

1091 second ranked in all other cases). We attribute this to two reasons: 1) classification algorithm 1092 accuracies depend vastly on the resolution of the satellites, and 2) the training data that we used 1093 for the SVMs were derived from other satellite products (of higher resolutions than Landsat).

1094 The literature review reflects a variety of resolutions and sources as opposed to our use of $30 \mathrm{~m}$

1095 Landsat imagery for all the case studies. On the other hand, some studies used in-situ field 1096 measurements as training data which likely led to higher classification accuracy. However, given 1097 the almost similar accuracies of unsupervised classification and SVM, we recommend the prior 1098 (as SVMs require good training data and takes time for algorithm development) for deltaic 1099 feature detection based on Landsat imagery.

1100 In a synergistic study, Munasinghe et al. (under review) evaluated 5 conventional remote sensing 1101 techniques (the same as used in this study) on 44 global river deltas worldwide in an attempt to 
1102 infer on the performance of techniques in shoreline extraction in different types of deltas (River,

1103 Tide, Wave-dominated) in different geographic/climatic regions. A major goal of that study was

1104 to draw common generalizations and working behaviors of techniques around well-known types

1105 of deltas and apply them to lesser studied, data sparse regions. Results showed that Unsupervised

1106 classification yielded the best performance for the majority of the deltas (35 of 44) whilst

1107 supervised classification yielded the best for the remainders ( 9 of 44$)$. They also found that

1108 extraction accuracies were higher in wave dominated deltas, lower for tide-dominated deltas, and

1109 moderate for river-dominated deltas. Reasons were attributed to the alongshore sediment

1110 transport processes of the wave-dominated deltas, resulting in sandy shorelines which has higher

1111 contrast with the less-muddied ocean making it easier for land-water boundary identification. In

1112 comparison, sediment-rich murky waters in the nearshore environment governed by the intertidal

1113 oscillations in tide-dominated deltas provided less contrast with land. Hence reduced extraction

1114 accuracies. Based on results of both these studies, we recommend the use of Unsupervised

1115 Classification as a first order extraction technique for data sparse deltas or previously unstudied

1116 deltaic regions.

\section{$1117 \quad 7 . \quad$ Future Directions}

1118 Based on our evaluation of the literature, we see four areas which we deem most opportune for

1119 future development:

1120 Direction 1: Utilization of higher resolution imagery and developing better sub-pixel data 1121 mining techniques

1122 An important aspect that we recognized earlier was that, compared to shoreline changes, there

1123 was a dearth in the number of studies that focused on other environmental indicators of delta 
1124 morphology change. This was explained by the fact that the shoreline governs the effective

1125 landmass that is suitable for human use and is prudent to know the progradation and degradation

1126 of a delta against sea level rise and fast changing climatic conditions. Consequently, shoreline

1127 change studies, evidently, seem to have greater weightage and research merit than other

1128 indicators. We, however, would like to bring out a different perspective to the problem in

1129 recognizing that technological limitation is also an important governing factor of these disparate

1130 numbers. Specifically, the spatial resolutions of earth observing satellites that are used to detect

1131 environmental indicators of river delta morphology change.

1132 Detecting the shoreline of a delta, although as described earlier is quite complicated, can be

1133 performed relatively well with imagery with moderate spatial resolution (in the range of $30-250$

$1134 \mathrm{~m})$. On the other hand, detecting crevasse splays, channel avulsions and anastomosis of channels

1135 with a high level of accuracy, especially in smaller channels and topographically challenging

1136 regions, require very high-resolution satellite imagery (below $10 \mathrm{~m}$ ). The problem is exacerbated

1137 if these changes are required to be detected in particularly small deltas, as the background noise

1138 from surrounding, non-deltaic, features can heavily influence these analyses.

1139 In the last decade, we experienced a great increase in the availability of higher resolution satellite

1140 imagery, primarily through commercial space programs (e.g. Planet Labs, Airbus Defense and

1141 Space, Inc.). These sub-meter resolution platforms could be instrumental in detecting intricate

1142 deltaic features. Striving for higher resolutions, however, comes at a cost. With an exception of

1143 programs that provide conditional access to high resolution satellite archives (e.g. Planet labs),

1144 most of these platforms are payment-based, and imagery acquisition could be a significant

1145 proponent of the project budget. Costs also include data storage and purchase and maintenance

1146 of high-powered computational systems. Due to exorbitant costs, and also due to limited archival 
1147 length (since most of these platforms are new, the length of their archives is not sufficient for 1148 delta change studies), the usage of higher resolution platforms is still limited in deltaic research.

1149 However, it can be expected that, as time progresses, the use of these platforms will increase 1150 dramatically.

1151 In the meantime, fusion of high and medium resolution imagery for detecting fine resolution 1152 deltaic features is one promising way forward. Image fusion and the consequent overall increase 1153 in resolution presents a solution to another problem: presence of mixed pixels in shoreline 1154 classification. As described earlier, this issue has been recognized as a major problem 1155 influencing the accuracy of remote-sensing image classification (Liu et al., 2016). Theoretically, 1156 with improvements in imagery spatial resolution, the number of mixed pixels will be greatly 1157 decreased (Wu, 2009).

1158 There is also great potential in developing novel data mining algorithms, especially sub-pixel 1159 algorithms (which have historically shown success in the literature) that can be used with already 1160 existing moderate spatial resolution platforms. Examples of such algorithms, which were 1161 recently applied to delta morphology studies, include the grid-based colocation pattern mining 1162 technique (Sainju and Zhang, 2017), Spectral Unmixing Algorithm Based on Distance Geometry 1163 (Pu et al., 2013), and the use of colorimetry to estimate the proportion of classes in mixed pixels 1164 (Suresh and Jain, 2018). Finding solutions to sub-pixel information will not only help advance 1165 morphological science forward but could also provide great impetus to the studies that will be 1166 forthcoming using high resolution satellite imagery. 
1167 Direction 2: Use of automated pattern recognition techniques, universal applicability and 1168 algorithm transferability across platforms

1169 Although there exist several manual/semi-automated methods to extract information from

1170 satellite imagery as discussed in the sections above, we see great advantages in extraction of

1171 information though automated techniques for change detection which could reduce the errors due

1172 to operator bias and more efficiently partition and recognize patterns and relationships in

1173 datasets.

1174 In this context, we think that "Smart Data Discovery - the idea of automating the identification of 1175 patterns and trends in large data sets" (Sallam et al., 2017) - can play an important role in feature 1176 extraction from satellite big data. Smart data discovery is currently used increasingly in the 1177 business intelligence sector in making informed market decisions (Sallam et al., 2017). We think 1178 however, that there is great potential for this technique in the domain of satellite remote sensing 1179 to prepare and cleanse data more intelligently, automatically find hidden patterns and 1180 correlations in data, especially where traditional and even semi-automatic machine learning 1181 techniques are expensive, difficult and time intensive to implement.

1182 Algorithms that we develop also need to be near-universally applicable. Localized algorithms 1183 which work perfectly in one particular region or for a particular size and type of delta often do 1184 not perform well in other locations and is thus of relatively limited use elsewhere. To the holistic 1185 study of Earth's geomorphology and its evolution, continental deltaic dynamics is warranted.

1186 There is importance of looking at how these landforms change at large scales, hence, the need for 1187 universal techniques. Such techniques are, unfortunately, have yet to be developed. 
1188 It is to be expected that the number of remote sensing application of delta morphology analysis

1189 will increase in the near future due to continued extensions of freely-available satellite imagery

1190 archives (e.g. Landsat, MODIS), and increased availability of higher resolution imagery via

1191 commercial and government platforms. It is therefore important to promote algorithm

1192 developments with the capability to be transferred across platforms (e.g. to efficiently upscale

1193 and downscale information from different spatial resolutions). This will enhance their longevity

1194 and utility to the entire constellation of satellites.

\section{Direction 3: Improvement of Ancillary data}

1196 In our and others' view, inclusion of additional explanatory variables that can differentiate

1197 spectral classes is more promising than enhancement of the image processing technique alone

1198 (Khatami et al., 2016). Common examples include topographic data such as digital elevation

1199 models, slope, aspect layers, geological layers, data from active sensors such as synthetic

1200 aperture radar or LiDAR, data from passive sensors, data from different temporal rates of

1201 phenological changes in vegetation mapping, and anisotropy of land surface reflectance. The

1202 inclusion of such data gives additional data layers of information that can be utilized in the

1203 problem-solving framework (e.g. Figure 7: The additional information that contributes to the

1204 understanding of deltaic evolution) to solve for the complexities of the deltaic environment more

1205 easily.

1206 There exist challenges, however, in collecting ancillary data. Firstly, there is a regional disparity

1207 in the quantity of data collected. Although data is abundantly collected and housed in most of the

1208 economically developed countries of the world, data collection is sparse in the developing

1209 countries. Second is the bureaucracy of organizations which own these data. The lack of open 
1210 data policies makes it difficult for researchers to access them. Thirdly, the culture of data sharing

1211 among researchers. Research culture should orient itself in a direction of openly sharing data

1212 subsequent to your own research for other interested parties to build up on. This culture is

1213 gathering momentum through public platforms like GitHub, researchgate, HydroShare, and stack

1214 exchanges. We however, envision the need of more subject-specific research repositories.

\section{Direction 4: A Global Information System of deltaic data}

1216 One of the major challenges for researchers working in the domain of deltaic remote sensing is

1217 that there is a lack of ground truth data to validate their observations against. On the other hand,

1218 field geomorphologists, who base their research efforts on identifying changes in deltaic features

1219 on a local scale, would immensely benefit from the "bigger picture" of the deltaic domain from

1220 the remote sensing community. One of the major challenges has been to build a data sharing

1221 bridge between these two communities. There currently exists no portal/database/repository

1222 which offers different types of data in relation to deltaic research. A repository for river deltaic

1223 research similar to, for example, HydroShare should be established. HydroShare (Tarboton et al.,

1224 2014), operated by the Consortium of Universities for the Advancement of Hydrologic Science,

1225 Inc. (CUAHSI), is an online collaboration environment for sharing data, models, and code

1226 related to hydrology. A delta repository could (conceptually) include field data (e.g. soil types,

1227 point climate data, different land use types) collected by field researchers, remotely sensed data

1228 (e.g. locations and extents of deltaic features, land use class delineations, temporal change of

1229 features), different numerical models which model deltaic features (e.g. crevasse splays,

1230 avulsions, shoreline changes), and publicly volunteered and vetted geographic information. We

1231 believe that such a repository will foster collaborative and interdisciplinary research and help to

1232 propel deltaic research to the next level. 


\section{$1233 \quad$ 8. Conclusions}

1234 River deltas are important landforms that serve many societal and ecological functions.

1235 Assessing changes to delta morphology is important to identify vulnerable areas and sustainably

1236 manage deltaic land. Satellite remote sensing provides an effective way of detecting delta

1237 morphology change over time.

1238 This review focused on Remote Sensing Techniques that are used in detecting delta morphology

1239 change. We discussed 18 such techniques, their strengths and their caveats with regard to deltaic

1240 feature extraction and change detection. Review of literature suggests that sub-pixel algorithms

1241 such as spectral mixture analysis and Fuzzy logic yield very high accuracies, while machine

1242 learning techniques ranked second. Support Vector Machines rank as the best individual machine

1243 learning technique across reviewed literature. We also found that the use of an ensemble of

1244 techniques (a machine learning technique ensemble, or a mix of machine learning and

1245 conventional ones) yield high accuracies.

1246 The choice of the technique(s) that one should preferably use to extract features of a river delta is 1247 governed primarily by the complexity of the delta. Simple deltas can be analyzed using relatively

1248 simple techniques and vice versa. We also found that the choice of technique depends on how

1249 data intensive the algorithm is, the availability of resources (time and computational resource),

1250 and the skill level of the user (e.g. machine learning applications requires specific skillsets). A

1251 comparison study performed between 10 deltas using 7 algorithms yielded unsupervised

1252 classification as the go-to method for quick and robust delta-morphology-indicator detection.

1253 We discuss the pathway forward for future research by recognizing the utility of using different

1254 delta morphology remote sensing techniques on one particular river delta to gain a better 
understanding of its landmass evolution, and also of the importance of comparison studies across deltas to infer on the similarities/dissimilarities of morphological changes and identify strengths limitations of remote sensing techniques themselves in different geographic/climatic conditions.

Four directions in which how future research will benefit are presented. The importance of higher spatial resolutions and the need for the development of more robust sub-pixel detection algorithms to mine data from moderate resolution imagery to more accurately infer on deltaic features such as smaller channel avulsions and formation of splays, is highlighted. The importance of automated pattern recognition techniques, universal applicability of algorithms, and algorithm-transferability across platforms are discussed. Thirdly, the effective use of ancillary data to make better judgement calls during the deltaic feature extraction process are brought forth, and finally, the concept of a repository which houses different types of data and models pertaining to deltaic research which is envisioned to foster interdisciplinary collaboration are opined.

\section{References}

Adams, J.B., Sabol, D.E., Kapos, V., Almeida Filho, R., Roberts, D.A., Smith, M.O., Gillespie, A.R., 1995. Classification of multispectral images based on fractions of endmembers: Application to land-cover change in the Brazilian Amazon. Remote sensing of Environment, 52(2), 137-154. https://doi.org/10.1016/0034-4257(94)00098-8

Adam, E M., Mutanga, O., Rugege, D., Ismail, R., 2012. Discriminating the papyrus vegetation (Cyperus papyrus L.) and its co-existent species using random forest and hyperspectral data resampled to HYMAP. International Journal of Remote Sensing, 33(2), 552-569. https://doi.org/10.1080/01431161.2010.543182

Adegoke, J.O., Fageja, M., James, G., Agbaje, G., Ologunorisa, T.E., 2010. An assessment of recent changes in the Niger Delta coastline using satellite imagery. Journal of Sustainable Development, 3(4), 277. https://doi.org/10.5539/jsd.v3n4p277

Ahmed, A., Drake, F., Nawaz, R., Woulds, C., 2018. Where is the coast? Monitoring coastal land dynamics in Bangladesh: An integrated management approach using GIS and remote sensing 
techniques. Ocean \& Coastal Management, 151, 10-24.

1284 Akar, Ö., and Güngör, O., 2015. Integrating Multiple Texture Methods and NDVI to the Random 1285 Forest Classification Algorithm to Detect Tea and Hazelnut Plantation Areas in Northeast 1286 Turkey. International Journal of Remote Sensing 36(2): 442-464.

1287 https://doi.org/10.1080/01431161.2014.995276

1288 Alesheikh, A.A., Ghorbanali, A., Nouri, N., 2007. Coastline change detection using remote 1289 1290 sensing. International Journal of Environmental Science \& Technology, 4(1), 61-66. https://doi.org/10.1007/BF03325962

Al Fugura, A., Billa, L., Pradhan, B., 2011. Semi-automated procedures for shoreline extraction using single RADARSAT-1 SAR image. Estuarine, Coastal and Shelf Science, 95(4), 395-400. https://doi.org/10.1016/j.ecss.2011.10.009

Allen, Y. C., Couvillion, B. R., Barras, J. A., 2012. Using multitemporal remote sensing imagery 1295 and inundation measures to improve land change estimates in coastal wetlands. Estuaries and 1296 Coasts, 35(1), 190-200. https://doi.org/10.1007/s12237-011-9437-z Allison, M.A., Khan, S.R., Goodbred Jr, S.L., Kuehl, S.A., 2003. Stratigraphic evolution of the late Holocene Ganges-Brahmaputra lower delta plain. Sedimentary Geology, 155(3-4), 317-342. https://doi.org/10.1016/S0037-0738(02)00185-9 potential to operationalize shoreline sensitivity mapping: Classifying multiple Wide Fine Quadrature Polarized RADARSAT-2 and Landsat 5 scenes with a single Random Forest model. Remote Sensing, 7(10), 13528-13563. https://doi.org/10.3390/rs71013528 A comparative study of NOAA-AVHRR derived drought indices using change vector analysis. Remote Sensing of Environment, 105(1), 9-22. https://doi.org/10.1016/j.rse.2006.06.003 case study over the Bosphorus. Journal of Coastal Research, 983-991. https://doi.org/10.2112/07$\underline{0825.1}$

Bendsen, H., Meyer, T., 2002. The dynamics of land use systems in Ngamiland: Changing livelihood options and strategies. In: Environmental Monitoring of Tropical Wetlands, Proceedings of a Wetland Conference, Maun, Botswana (pp. 278-304).

Berberoglu, S., Lloyd, C.D., Atkinson, P.M., Curran, P.J., 2000. The integration of spectral and textural information using neural networks for land cover mapping in the Mediterranean.

1316 Berhane, T., Lane, C., Wu, Q., Autrey, B., Anenkhonov, O., Chepinoga, V., Liu, H., 2018.

1317 Decision-tree, rule-based, and random forest classification of high-resolution multispectral 
1318 imagery for wetland mapping and inventory. Remote sensing, 10(4), 580.

1319 https://doi.org/10.3390/rs10040580

1320 Blaschke, T., 2010. Object based image analysis for remote sensing. ISPRS Journal of Photogrammetry and Remote Sensing, 65(1), 2-16.

1322 https://doi.org/10.1016/j.isprsjprs.2009.06.004

1323 Braud, D.H., Feng, W., 1998. Semi-automated construction of the Louisiana coastline digital 1324 land/water boundary using Landsat Thematic Mapper satellite imagery (Department of 1325 Geography and Anthropology, Louisiana State University, Louisiana Applied Oil Spill Research 1326 and Development Program), OSRAPD Technical Report. 97-002.

1327 Breiman, L., 2001. Random forests. Machine learning, 45(1), 5-32.

1328 https://doi.org/10.1023/A:1010933404324

1329 Buono, A., Nunziata, F., Migliaccio, M., Yang, X., Li, X., 2017. Classification of the Yellow 1330 River delta area using fully polarimetric SAR measurements. International journal of remote 1331 sensing, 38(23), 6714-6734. https://doi.org/10.1080/01431161.2017.1363437

1332 Cao, M., Liu, G., Zhang, X., 2007. An object-oriented approach to map wetland vegetation: a 1333 case study of yellow river delta. In 2007 IEEE International Geoscience and Remote Sensing 1334 Symposium. pp 4585-4587.

1335 Chen, J., Gong, P., He, C., Pu, R., Shi, P., 2003. Land-use/land-cover change detection using 1336 1337 improved change-vector analysis. Photogrammetric Engineering \& Remote Sensing, 69(4), 369379. https://doi.org/10.14358/PERS.69.4.369

Chen, C., Fu, J., Zhang, S., Zhao, X., 2019. Coastline information extraction based on the tasseled cap transformation of Landsat-8 OLI images. Estuarine, Coastal and Shelf Science, 217, 281-291. https://doi.org/10.1016/j.ecss.2018.10.021

Chu, Z.X., Sun, X.G., Zhai, S.K., Xu, K.H., 2006. Changing pattern of accretion/erosion of the modern Yellow River (Huanghe) subaerial delta, China: Based on remote sensing images. Marine Geology, 227(1-2), 13-30. https://doi.org/10.1016/j.margeo.2005.11.013 Ciavola, P., 1999. Relation between river dynamics and coastal changes in Albania: an assessment integrating satellite imagery with historical data. International Journal of Remote Sensing, 20(3), 561-584. https://doi.org/10.1080/014311699213343

Civco, D.L., Hurd, J.D., Wilson, E.H., Song, M., Zhang, Z., 2002. A comparison of land use and land cover change detection methods. In ASPRS-ACSM Annual Conference (Vol. 21). method for mapping forest clearcuts in the Pacific Northwest using Landsat imagery. Photogrammetric Engineering and Remote Sensing, 64(4), 293-299. 149. 
1355 Congalton, R.G., 1991. A review of assessing the accuracy of classifications of remotely sensed 1356 data. Remote sensing of environment, 37(1), 35-46.

1357 Crist, E.P., 1985. A TM tasseled cap equivalent transformation for reflectance factor data.

1358 Remote Sensing of Environment, 17(3), 301-306.

1359 Cui, B. L., Li, X. Y., 2011. Coastline change of the Yellow River estuary and its response to the 1360 sediment and runoff (1976-2005). Geomorphology, 127(1-2), 32-40. https://doi.org/10.1016/j.geomorph.2010.12.001

Dada, O. A., Li, G., Qiao, L., Asiwaju-Bello, Y. A., Anifowose, A. Y. B., 2018. Recent Niger Delta shoreline response to Niger River hydrology: Conflict between forces of Nature and Humans. Journal of African Earth Sciences, 139, 222-231.

https://doi.org/10.1016/j.jafrearsci.2017.12.023

1366 Da Silva, A. G. A., Stattegger, K., Vital, H., \& Schwarzer, K. (2019). Coastline change and 1367 offshore suspended sediment dynamics in a naturally developing delta (Parnaíba Delta, NE Brazil). Marine Geology, 410, 1-15. https://doi.org/10.1016/j.margeo.2018.12.013

Del Frate, F., Latini, D., Minchella, A., Palazzo, F., 2012. A new automatic technique for coastline extraction from SAR images. In: SAR Image Analysis, Modeling, and Techniques XII (Vol. 8536, p. 85360R). International Society for Optics and Photonics.

Dellepiane, S., De Laurentiis, R., Giordano, F., 2004. Coastline extraction from SAR images and a method for the evaluation of the coastline precision. Pattern Recognition Letters, 25(13), 14611470. https://doi.org/10.1016/j.patrec.2004.05.022

Demers, A.M., Banks, S.N., Pasher, J., Duffe, J., Laforest, S., 2015. A comparative analysis of object-based and pixel-based classification of RADARSAT-2 C-band and optical satellite data 1-19. https://doi.org/10.1080/07038992.2015.1020361

Deng, J.S., Wang, K., Deng, Y.H., Qi, G.J., 2008. PCA-based land-use change detection and analysis using multitemporal and multisensor satellite data. International Journal of Remote Sensing, 29(16), 4823-4838. https://doi.org/10.1080/01431160801950162

Denison, D.G., Mallick, B.K., Smith, A.F., 1998. A bayesian CART algorithm. Biometrika, 85(2), 363-377. https://doi.org/10.1093/biomet/85.2.363 monitoring in a part of the northern coastal area of Java, Indonesia. Remote sensing, 8(3), 190. https://doi.org/10.3390/rs8030190

1391

Ding, W.J., Wang, R.Q., Wu, D.Q., Liu, J., 2013. Cellular automata model as an intuitive approach to simulate complex land-use changes: an evaluation of two multi-state land-use models in the Yellow River Delta. Stochastic Environmental Research and Risk Assessment, 27(4), 899-907. https://doi.org/10.1007/s00477-012-0624-7 
Ekercin, S., 2007. Coastline change assessment at the Aegean Sea coasts in Turkey using multitemporal Landsat imagery. Journal of Coastal Research, 691-698. https://doi.org/10.2112/04-0398.1

1395

El-Asmar, H.M., Hereher, M.E., 2011. Change detection of the coastal zone east of the Nile Delta using remote sensing. Environmental Earth Sciences, 62(4), 769-777. https://doi.org/10.1007/s12665-010-0564-9

Elhag, M., Psilovikos, A., Sakellariou-Makrantonaki, M., 2013. Land use changes and its impacts on water resources in Nile Delta region using remote sensing techniques. Environment, Development and Sustainability, 15(5), 1189-1204. https://doi.org/10.1007/s10668-013-9433-5

El-Kawya, O.A., Rød, J.K., Ismail, H.A., Suliman, A.S., 2011. Land use and land cover change detection in the western Nile delta of Egypt using remote sensing data. Applied Geography, 31(2), 483-494. https://doi.org/10.1016/j.apgeog.2010.10.012

El Raey, M., Nasr, S.M., Frihy, O.E., El Hattab, M.M., 1995. Change detection of Rosetta promontory over the last forty years. International Journal of Remote Sensing, 16, 825-834 https://doi.org/10.1080/01431169508954446

El-Raey, M., El-Din, S.S., Khafagy, A.A., Abo Zed, A.I., 1999. Remote sensing of beach erosion/accretion patterns along Damietta-Port Said shoreline, Egypt. International Journal of Remote Sensing, 20(6), 1087-1106. https://doi.org/10.1080/014311699212867

Elliott T., 1986. Deltas. In: Reading H.G. (Ed.) Sedimentary Environments and Facies, Blackwell Scientific Publications, Oxford, pp. 113-154.

Enderle, D.I., Weih Jr, R.C., 2005. Integrating supervised and unsupervised classification methods to develop a more accurate land cover classification. Journal of the Arkansas Academy of Science, 59(1), 65-73.

Foody, G.M., McCulloch, M.B., Yates, W.B., 1995. Classification of Remotely Sensed Data by an Artificial Neural Network: Issues Related to Training Data. Photogrammetric Engineering \& Remote Sensing, 61(4), 391-401.

Foody, G.M., Mathur, A., 2006. The use of small training sets containing mixed pixels for accurate hard image classification: Training on mixed spectral responses for classification by a SVM. Remote sensing of Environment, 103(2), 179-189.

https://doi.org/10.1016/j.rse.2006.04.001

Foody, G.M., Muslim, A.M., Atkinson, P.M., 2005. Super-resolution mapping of the waterline from remotely sensed data. International Journal of Remote Sensing, 26(24), 5381-5392.

https://doi.org/10.1080/01431160500213292

Frazier, P.S., Page, K.J., 2000. Water body detection and delineation with Landsat TM data, Photogrammetric Engineering \& Remote Sensing, 66 (2), 1461-1467. 
Friedl, M.A., Brodley, C.E., 1997. Decision tree classification of land cover from remotely sensed data. Remote sensing of Environment, 61(3), 399-409. https://doi.org/10.1016/S0034$\underline{4257(97) 00049-7}$

Frihy, O.E., Dewidar, K.M., Nasr, S.M., El Raey, M.M., 1998. Change detection of the northeastern Nile Delta of Egypt: shoreline changes, Spit evolution, margin changes of Manzala lagoon and its islands. International Journal of Remote Sensing, 19(10), 1901-1912. https://doi.org/10.1080/014311698215054

Frohn, R.C., D’Amico, E., Lane, C., Autrey, B., Rhodus, J., Liu , H., 2012. Multi-temporal subpixel Landsat ETM+ classification of isolated wetlands in Cuyahoga County, Ohio, USA. Wetlands, 32(2), 289-299. https://doi.org/10.1007/s13157-011-0254-8

Ghanavati, E., Firouzabadi, P.Z., Jangi, A.A., Khosravi, S., 2008. Monitoring geomorphologic changes using Landsat TM and ETM+ data in the Hendijan River delta, southwest Iran. International Journal of Remote Sensing, 29(4), 945-959. https://doi.org/10.1080/01431160701294679

\section{Ghoneim, E., Mashaly, J., Gamble, D., Halls, J., AbuBakr, M., 2015. Nile Delta exhibited a} spatial reversal in the rates of shoreline retreat on the Rosetta promontory comparing pre-and post-beach protection. Geomorphology, 228, 1-14. https://doi.org/10.1016/j.geomorph.2014.08.021

Gislason, P.O., Benediktsson, J.A., Sveinsson, J.R., 2006. Random forests for land cover classification. Pattern Recognition Letters, 27(4), 294-300.

https://doi.org/10.1016/j.patrec.2005.08.011

Gong, P., 1993. Change detection using Principal Component Analysis and Fuzzy set theory. Canadian Journal of Remote Sensing, 19(1), 22-29. https://doi.org/10.1080/07038992.1993.10855147

Gopinath, G., Seralathan, P., 2005. Rapid erosion of the coast of Sagar island, West BengalIndia. Environmental Geology, 48(8), 1058-1067. https://doi.org/10.1007/s00254-005-0044-9

Gou, S., Li, X., Yang, X., 2016. Coastal zone classification with fully polarimetric SAR imagery. IEEE Geoscience and Remote Sensing Letters, 13(11), 1616-1620.

https://doi.org/10.1109/LGRS.2016.2597965

Guariglia, A., Buonamassa, A., Losurdo, A., Saladino, R., Trivigno, M.L., Zaccagnino, A., Colangelo, A., 2006. A multisource approach for coastline mapping and identification of shoreline changes. Annals of geophysics, 49(1).

Gugliotta, M., Saito, Y., 2019. Matching trends in channel width, sinuosity, and depth along the fluvial to marine transition zone of tide-dominated river deltas: The need for a revision of depositional and hydraulic models. Earth-science reviews.

https://doi.org/10.1016/j.earscirev.2019.02.002 

vulnerability to sea level rise. Journal of Geophysical Research: Earth Surface, 116(F2). https://doi.org/10.1029/2010JF001891

Haas, J., Ban,Y., 2014. Urban growth and environmental impacts in Jing-Jin-Ji, the Yangtze, River Delta and the Pearl River Delta. International Journal of Applied Earth Observation and Geoinformation, 30, 42-55. https://doi.org/10.1016/j.jag.2013.12.012

Heimann, T., Thorn, M., Kunert, T., Meinzer, H.P., 2004. New methods for leak detection and contour correction in seeded region growing segmentation. In 20th ISPRS Congress, Istanbul

1471 (Vol. 35, pp. 317-322).

1472 Heumann, B.W., 2011. An object-based classification of mangroves using a hybrid decision tree-Support vector machine approach. Remote Sensing, 3(11), 2440-2460. https://doi.org/10.3390/rs3112440

Huang, Z., Lees, B.G., 2004. Combining non-parametric models for multisource predictive forest mapping. Photogrammetric Engineering and Remote Sensing, 70(4), pp. 415-425. https://doi.org/10.14358/PERS.70.4.415

1478 Hutchings, R.M., Campbell, S.K., 2005. The Importance of Deltaic Wetland Resources: A Perspective from the Nooksack River Delta, Washington State. Journal of Wetland Archaeology, 5(1): 17-34. https://doi.org/10.1179/jwa.2005.5.1.17 remotely sensed images by singularity analysis. IEEE Geoscience and Remote Sensing Letters, 12(11), 2218-2221. https://doi.org/10.1109/LGRS.2015.2458898 imagery. Computers \& Geosciences, 22(9), 959-967. https://doi.org/10.1016/S0098$\underline{3004(96) 00034-9}$ Edition, Englewood Cliffs, NJ: Prentice-Hall.

Kamal, M., Phinn, S., 2011. Hyperspectral data for mangrove species mapping: A comparison of pixel-based and object-based approach. Remote Sensing, 3(10), 2222-2242.

https://doi.org/10.3390/rs3102222

1492 Kelley, G.W., Hobgood, J.S., Bedford, K.W., Schwab D.J., 1998. Generation of threehttps://doi.org/10.1175/1520-0434(1998)013<0659:GOTDLM>2.0.CO;2 practitioners and future research. Remote Sensing of Environment, 177, 89-100.

1498 https://doi.org/10.1016/j.rse.2016.02.028 
Kim, M., Warner, T.A., Madden, M., Atkinson, D.S., 2011. Multi-scale GEOBIA with very high spatial resolution digital aerial imagery: Scale, texture and image objects. International Journal of Remote Sensing, 32(10), 2825-2850. https://doi.org/10.1080/01431161003745608 2015. Evolution of the Yellow River Delta and its relationship with runoff and sediment load from 1983 to 2011. Journal of Hydrology, 520, 157-167. https://doi.org/10.1016/j.jhydrol.2014.09.038

1506

1507

1508

1509

1510

1511

1512

1513

1514

1515

1516

1517

1518

1519

1520

1521

1522

1523

1524

1525

1526

1527

1528

1529

1530

1531

1532

1533

1534

1535

Krause, G., Bock, M., Weiers, S., Braun, G., 2004. Mapping land-cover and mangrove structures with remote sensing techniques: A contribution to a synoptic GIS in support of coastal management in North Brazil. Environ. Manage., 34(3), 429-440. https://doi.org/10.1007/s00267004-0003-3

Kuenzer, C., van Beijma, S., Gessner, U., Dech, S., 2014. Land surface dynamics and environmental challenges of the Niger Delta, Africa: Remote sensing-based analyses spanning three decades (1986-2013). Applied Geography, 53, 354-368.

https://doi.org/10.1016/j.apgeog.2014.07.002

Kuleli, T., 2010. Quantitative analysis of shoreline changes at the Mediterranean Coast in Turkey. Environmental monitoring and assessment, 167(1-4), 387-397. https://doi.org/10.1007/s10661-009-1057-8

Kundu, S., Mondal, A., Khare, D., Mishra, P.K., Shukla, R., 2014. Shifting shoreline of Sagar Island Delta, India. Journal of maps, 10(4), 612-619.

https://doi.org/10.1080/17445647.2014.922131

Kushwaha, S.P.S., Dwivedi, R.S., Rao, B.R.M., 2000. Evaluation of various digital image processing techniques for detection of coastal wetlands using ERS-1 SAR data. International Journal of Remote Sensing, 21(3), 565-579. https://doi.org/10.1080/014311600210759

Le, M. H., Hitoshi, T., Nguyen, T. T., Nguyen, T.V., 2006. Prediction of river bank erosion in the lower Mekong river delta. In Vietnam-Japan Estuary workshop, Hanoi, Vietnam. pp. 22-24.

Le Moigne, J., Tilton, J.C., 1995. Refining image segmentation by integration of edge and region data. IEEE Transactions on Geoscience and Remote Sensing, 33(3), 605-615. https://doi.org/10.1109/36.387576

Le, T.V.H., Nguyen, H. N., Wolanski, E., Tran, T.C., Haruyama, S., 2007. The combined impact on the flooding in Vietnam's Mekong River delta of local man-made structures, sea level rise, and dams upstream in the river catchment. Estuarine, Coastal and Shelf Science, 71(1-2), 110116. https://doi.org/10.1016/j.ecss.2006.08.021

Lee, K.S., Kim, T.H., Yun, Y.S., Shin, S.M., 2001. Spectral characteristics of shallow turbid water near the shoreline on inter-tidal flat. Korean Journal of Remote Sensing, 17(2), 131-139.

Lee, J. S., Jurkevich, I., 1990. Coastline detection and tracing in SAR images. IEEE Transactions on Geoscience and Remote Sensing, 28(4), 662-668. https://doi.org/10.1109/TGRS.1990.572976 
Lentz, E. E., Thieler, E.R., Plant, N.G., Stippa, S.R., Horton, R.M., Gesch, D.B., 2016. Evaluation of dynamic coastal response to sea-level rise modifies inundation likelihood. Nature Climate Change, 6(7), 696. https://doi.org/10.1038/nclimate2957

Li, H.T., Gu, H.Y., Han, Y.S., Yang, J., 2010. Object-oriented classification of high-resolution remote sensing imagery based on an improved colour structure code and a support vector machine. International Journal of Remote Sensing, 31(6), 1453-1470. https://doi.org/10.1080/01431160903475266

Li, J., Donselaar, M. E., Aria, S.E.H., Koenders, R., Oyen, A.M., 2014. Landsat imagery-based visualization of the geomorphological development at the terminus of a dryland river system. Quaternary international, 352, 100-110. https://doi.org/10.1016/j.quaint.2014.06.041

Li, J., Bristow, C.S., 2015. Crevasse splay morphodynamics in a dryland river terminus: Río Colorado in Salar de Uyuni Bolivia. Quaternary International, 377, 71-82. https://doi.org/10.1016/j.quaint.2014.11.066

Li, X., Yeh, A.G.O., 1998. Principal component analysis of stacked multi-temporal images for the monitoring of rapid urban expansion in the Pearl River Delta. International Journal of Remote Sensing, 19(8), 1501-1518. https://doi.org/10.1080/014311698215315

Li, X., Yeh, A. G. O., 2004. Analyzing spatial restructuring of land use patterns in a fast growing region using remote sensing and GIS. Landscape and Urban planning, 69(4), 335-354.

https://doi.org/10.1016/j.landurbplan.2003.10.033

Liu, G., Zhang, L., Zhang, Q., Musyimi, Z., Jiang, Q., 2014. Spatio-temporal dynamics of wetland landscape patterns based on remote sensing in Yellow River Delta, China. Wetlands, 34(4), 787-801. https://doi.org/10.1007/s13157-014-0542-1

Liu, J., Feng, Q., Gong, J., Zhou, J., Li, Y., 2016. Land-cover classification of the Yellow River Delta wetland based on multiple end-member spectral mixture analysis and a Random Forest classifier. International Journal of Remote Sensing, 37(8), 1845-1867. https://doi.org/10.1080/01431161.2016.1165888

Liu, X., Deng, R., Xu, J., Zhang, F., 2017. Coupling the modified linear spectral mixture analysis and pixel-swapping methods for improving subpixel water mapping: Application to the Pearl River Delta, China. Water, 9(9), 658. https://doi.org/10.3390/w9090658

Lohani B., Mason D.C., 1999. Construction of a digital elevation model of the Holderness Coast using the waterline method and Air-borne Thematic Mapper data. International Journal of Remote Sensing, 20(3): 593-607 https://doi.org/10.1080/014311699213361

Lodhi, M.A., Rundquist, D.C., Han, L., Juzila, M.S., 1997. The potential for remote sensing of loess soils suspended in surface water. Journal of the American Water Resources Association, 33(1), 111-127. https://doi.org/10.1111/j.1752-1688.1997.tb04087.x 
1571 Loos, E.A., Niemann, K.O., 2002. Shoreline feature extraction from remotely sensed imagery.

1572 In: International Geoscience and remote sensing symposium, 2002. IEEE Int. 6 (24-28), 3417-

1573 3419. https://doi.org/10.1109/IGARSS.2002.1027201

1574 Louati, M., Saïdi, H., Zargouni, F., 2015. Shoreline change assessment using remote sensing and

1575 GIS techniques: a case study of the Medjerda delta coast, Tunisia. Arabian Journal of

1576 Geosciences, 8(6), 4239-4255. https://doi.org/10.1007/s12517-014-1472-1

1577 Lu, D., Moran, E., Batistella, M., 2003. Linear mixture model applied to Amazonian vegetation

1578 classification. Remote Sensing of Environment, 87(4), 456-469.

1579 https://doi.org/10.1016/j.rse.2002.06.001

1580 Lu, D., Mausel, P., Batistella, M., Moran, E., 2004. Comparison of land-cover classification 1581 methods in the Brazilian Amazon Basin. Photogrammetric Engineering and Remote Sensing, 1582 70(6), 723-731. https://doi.org/10.14358/PERS.70.6.723

1583 Maiti, S., Bhattacharya, A.K., 2009. Shoreline change analysis and its application to prediction:

1584 A remote sensing and statistics based approach. Marine Geology, 257(1-4), 11-23.

1585 https://doi.org/10.1016/j.margeo.2008.10.006

1586 Mallinis, G., Emmanoloudis, D., Giannakopoulos, V., Maris, F., Koutsias, N., 2011. Mapping

1587 and interpreting historical land cover/land use changes in a Natura 2000 site using earth

1588 observational data: the case of Nestos delta, Greece. Applied Geography, 31(1), 312-320.

1589 https://doi.org/10.1016/j.apgeog.2010.07.002

1590 Malthus, T.J., Mumby, P.J., 2003. Remote sensing of the coastal zone: an overview and priorities 1591 for future research. International Journal of Remote Sensing, 24, 2805-2815.

1592 https://doi.org/10.1080/0143116031000066954

1593 Manavalan, P., Sathyanath, P., Rajegowda, G. L., 1993. Digital image analysis techniques to 1594 estimate waterspread for capacity evaluations of reservoirs. Photogrammetric Engineering and 1595 Remote Sensing, 59(9), 1389-1395.

1596 Marghany, M., Sabu, Z., Hashim, M., 2010. Mapping coastal geomorphology changes using 1597 synthetic aperture radar data. International Journal of Physical Sciences, 5(12), 1890-1896.

1598 Mas, J. F., 1999. Monitoring land-cover changes: a comparison of change detection techniques. 1599 International Journal of Remote Sensing, 20(1), 139-152.

1600 https://doi.org/10.1080/014311699213659

1601 Mas, J. F., Flores, J. J., 2008. The application of artificial neural networks to the analysis of 1602 remotely sensed data. International Journal of Remote Sensing, 29(3), 617-663.

1603 https://doi.org/10.1080/01431160701352154

1604 Mason, D. C., Davenport, I. J., 1996. Accurate and efficient determination of the shoreline in 1605 ERS-1 SAR images. IEEE Transactions on Geoscience and Remote Sensing, 34(5), 1243-1253. 1606 https://doi.org/10.1109/36.536540 
Masria, A., Nadaoka, K., Negm, A., Iskander, M., 2015. Detection of shoreline and land cover changes around Rosetta promontory, Egypt, based on remote sensing analysis. Land, 4(1), 216230. https://doi.org/10.3390/land4010216

Mathers, S., Zalasiewicz, J., 1999. Holocene sedimentary architecture of the Red River delta, Vietnam. Journal of Coastal Research, 314-325.

Mazid, M. M., Ali, S., Tickle, K.S., 2010. Improved C4. 5 algorithm for rule based classification. In Proceedings of the 9th WSEAS international conference on Artificial intelligence, knowledge engineering and data bases (pp. 296-301). World Scientific and Engineering Academy and Society (WSEAS).

Motsholapheko, M. R., Kgathi, D. L., Vanderpost, C., 2011. Rural livelihoods and household adaptation to extreme flooding in the Okavango Delta, Botswana. Physics and Chemistry of the Earth, 36(14-15), 984-995. https://doi.org/10.1016/j.pce.2011.08.004

Mouchot, M. C., Alföldi, T., De Lisle, D., McCullough, G., 1991. Monitoring the water bodies of the Mackenzie Delta by remote sensing methods. Arctic, 21-28.

https://doi.org/10.14430/arctic1566

Mukhopadhyay, A., Mukherjee, S., Mukherjee, S., Ghosh, S., Hazra, S., Mitra, D., 2012. Automatic shoreline detection and future prediction: A case study on Puri Coast, Bay of Bengal, India. European Journal of Remote Sensing, 45(1), 201-213.

https://doi.org/10.5721/EuJRS20124519

Munasinghe, D., Cohen, S., Huang, Y. F., Tsang, Y. P., Zhang, J., Fang, Z., 2018. Intercomparison of Satellite Remote Sensing-Based Flood Inundation Mapping Techniques. JAWRA Journal of the American Water Resources Association, 54(4), 834-846. https://doi.org/10.1111/1752-1688.12626

Munasinghe, D.S.N., Cohen, S., Hand, B., (under review), A Review of Satellite Remote Sensing Techniques of River Delta Morphology Change.

Mustard, J. F., Sunshine, J. M., 1999. Spectral analysis for earth science: investigations using remote sensing data. Remote sensing for the earth sciences: Manual of remote sensing, 3, 251307.

Nandi, S., Ghosh, M., Kundu, A., Dutta, D., Baksi, M., 2016. Shoreline shifting and its prediction using remote sensing and GIS techniques: a case study of Sagar Island, West Bengal (India). Journal of coastal conservation, 20(1), 61-80. https://doi.org/10.1007/s11852-015-0418-4

Nath, R. K., Deb, S. K., 2010. Water-body area extraction from high resolution satellite imagesan introduction, review, and comparison. International Journal of Image Processing (IJIP), 3(6), 265-384.

Niedermeier, A., Hoja, D., Lehner, S., 2005. Topography and morphodynamics in the German Bight using SAR and optical remote sensing data. Ocean Dynamics 55(2), 100-109. https://doi.org/10.1007/s10236-005-0114-2 
Niedermeier, A., Romaneessen, E., Lehner, S., 2000. Detection of coastlines in SAR images using wavelet methods. IEEE Transactions on Geoscience and Remote Sensing, 38(5), 22702281. https://doi.org/10.1109/36.868884

Nienhuis, J.H., Törnqvist, T.E., Esposito, C.R., 2018. Crevasse splays versus avulsions: A recipe for land building with levee breaches. Geophysical Research Letters, 45(9), 4058-4067. https://doi.org/10.1029/2018GL077933

Nitze, I., Grosse, G., 2016. Detection of landscape dynamics in the Arctic Lena Delta with temporally dense Landsat time-series stacks. Remote Sensing of Environment, 181, 27-41. https://doi.org/10.1016/j.rse.2016.03.038

Niya, A.K., Alesheikh, A.A., Soltanpor, M., Kheirkhahzarkesh, M.M., 2013. Shoreline change mapping using remote sensing and GIS. International Journal of Remote Sensing Applications, 3(3), 102-107.

Orton, G. J., Reading, H.G., 1993. Variability of deltaic processes in terms of sediment supply, with particular emphasis on grain size. Sedimentology, 40(3), 475-512. https://doi.org/10.1111/j.1365-3091.1993.tb01347.x

Ottinger, M., Kuenzer, C., Liu, G., Wang, S., Dech, S., 2013. Monitoring land cover dynamics in the Yellow River Delta from 1995 to 2010 based on Landsat 5 TM. Applied Geography, 44, 5368. https://doi.org/10.1016/j.apgeog.2013.07.003

Ozesmi, S.L., Bauer, M.E., 2002. Satellite remote sensing of wetlands. Wetlands ecology and management, 10(5), 381-402. https://doi.org/10.1023/A:1020908432489

Pal, M., Mather, P.M., 2003. An assessment of the effectiveness of decision tree methods for land cover classification. Remote sensing of Environment, 86(4), 554-565. https://doi.org/10.1016/S0034-4257(03)00132-9

Pal, M., Mather, P.M., 2005. Support vector machines for classification in remote sensing. International Journal of Remote Sensing, 26(5), 1007-1011. https://doi.org/10.1080/01431160512331314083

Paola, J.D., Schowengerdt, R.A., 1995. A review and analysis of backpropagation neural networks for classification of remotely-sensed multi-spectral imagery. International Journal of Remote Sensing, 16(16), 3033-3058. https://doi.org/10.1080/01431169508954607

Passalacqua, P., 2017. The Delta Connectome: A network-based framework for studying connectivity in river deltas. Geomorphology, 277, 50-62.

https://doi.org/10.1016/j.geomorph.2016.04.001

Petropoulos, G.P., Kalivas, D.P., Griffiths, H.M., Dimou, P.P., 2015. Remote sensing and GIS analysis for mapping spatio-temporal changes of erosion and deposition of two Mediterranean river deltas: The case of the Axios and Aliakmonas rivers, Greece. International Journal of Applied Earth Observation and Geoinformation, 35, 217-228.

https://doi.org/10.1016/j.jag.2014.08.004 
1681 Postma, G., 1995. Sea-level-related architectural trends in coarse-grained delta complexes.

1682 Sedimentary Geology, 98(1-4), 3-12. https://doi.org/10.1016/0037-0738(95)00024-3

1683 Pu, H., Xia, W., Wang, B., Jiang, G.M., 2013. A fully constrained linear spectral unmixing algorithm based on distance geometry. IEEE Transactions on Geoscience and Remote Sensing, 52(2), 1157-1176. https://doi.org/10.1109/TGRS.2013.2248013

Ryu, J.H., Won, J.S., Min, K.D., 2002. Waterline extraction from Landsat TM data in a tidal flat: a case study in Gomso Bay, Korea. Remote sensing of Environment, 83(3), 442-456. https://doi.org/10.1016/S0034-4257(02)00059-7

1689 Sallam, R.L., Howson, C., Idoine, C.J., 2017. Augmented Analytics Is the Future of Data and 1690 Analytics. https://www.gartner.com/en/documents/3773164

1691 Samarasinghe, S., 2016. Neural networks for applied sciences and engineering: from 1692 fundamentals to complex pattern recognition. Auerbach publications.

1693 Sanchez-Arcilla, A., Jimenez, J.A., Valdemoro, H.I., 2012. The Ebro Delta: morphodynamics 1694 and vulnerability. Journal of Coastal Research, 14(3).

1695 Sainju, A. M., Jiang, Z., 2017. Grid-based colocation mining algorithms on gpu for big spatial 1696 event data: A summary of results. In International Symposium on Spatial and Temporal Databases (pp. 263-280). Springer, Cham. https://doi.org/10.1007/978-3-319-64367-0_14 morphological changes due to river basin characteristics by means of remote sensing and GIS techniques. Water Science and technology, 48(10), 135-142.

1701 https://doi.org/10.2166/wst.2003.0558

1702

1703

1704

1705

1706

1707

1708

1709

1710

1711

1712

1713

1714

1715

1716
Seker, D.Z., Kaya, S., Musaoglu, N., Kabdasli, S., Yuasa, A., Duran, Z., 2005. Investigation of meandering in Filyos River by means of satellite sensor data. Hydrological Processes: An International Journal, 19(7), 1497-1508. https://doi.org/10.1002/hyp.5593

Serra, P., Pons, X., Sauri, D., 2003. Post-classification change detection with data from different sensors: Some accuracy considerations. International Journal of Remote Sensing, 24(16), 33113340. https://doi.org/10.1080/0143116021000021189

Seto, K.C., Woodcock, C.E., Song, C., Huang, X., Lu, J., Kaufmann, R.K., 2002. Monitoring land-use change in the Pearl River Delta using Landsat TM. International Journal of Remote Sensing, 23(10), 1985-2004. https://doi.org/10.1080/01431160110075532

Sgavetti, M., Ferrari, C., 1988. The use of TM data for the study of a modern deltaic depositional system. International Journal of Remote Sensing, 9(10-11), 1613-1627.

https://doi.org/10.1080/01431168808954964

Sha, Z., Bai, Y., Xie, Y., Yu, M., Zhang, L., 2008. Using a hybrid fuzzy classifier (HFC) to map typical grassland vegetation in Xilin River Basin, Inner Mongolia, China. International Journal of Remote Sensing, 29(8), 2317-2337. https://doi.org/10.1080/01431160701408436 
1717 Shalaby, A., Tateishi, R., 2007. Remote sensing and GIS for mapping and monitoring land cover 1718 and land-use changes in the Northwestern coastal zone of Egypt. Applied Geography, 27(1), 28-

1719 41. https://doi.org/10.1016/j.apgeog.2006.09.004

1720 Shen, F., Gao, A., Wu, J.P., Zhou, Y.X., Zhang, J., 2008. A remotely sensed approach on

1721 waterline ex- traction of silty tidal flat for DEM construction, a case study in Jiuduansha Shoal of

1722 Yangtze River. Acta Geodaetica et Cartographica Sinica, 37(1), 102-107.

1723 Shimabukuro, Y.E., Batista, G.T., Melio, E.M.K., Moreira, J.C., Duarte, V., 1998. Using shade

1724 fraction image segmentation to evaluate deforestation in Landsat Thematic Mapper images of the

1725 Amazon region. International Journal of Remote Sensing, 19(3), pp. 535-541.

1726 https://doi.org/10.1080/014311698216152

1727 Singh, S., Talwar, R., 2013. Review on different change vector analysis algorithms based change 1728 detection techniques. In: 2013 IEEE Second International Conference on Image Information

1729 Processing (ICIIP-2013) (pp. 136-141). IEEE. https://doi.org/10.1109/ICIIP.2013.6707570

1730 Small, C., 2004. The Landsat ETM+ spectral mixing space. Remote sensing of Environment, 1731 93(1-2), 1-17. https://doi.org/10.1016/j.rse.2004.06.007

1732 Steele, B.M., 2000. Combining multiple classifiers: an application using spatial and remotely 1733 sensed information for land cover type mapping. Remote Sensing of Environment, 74(3), 545556. https://doi.org/10.1016/S0034-4257(00)00145-0

Sun, N., Zhu, W., Cheng, Q., 2018. GF-1 and Landsat observed a 40-year wetland

1737 spatiotemporal variation and its coupled environmental factors in Yangtze River estuary. Estuarine, Coastal and Shelf Science, 207, 30-39. https://doi.org/10.1016/j.ecss.2018.03.022

Suresh, M., Jain, K., 2018. Subpixel level mapping of remotely sensed image using colorimetry. The Egyptian Journal of Remote Sensing and Space Science, 21(1), 65-72. https://doi.org/10.1016/j.ejrs.2017.02.004

Syvitski, J. P., Saito, Y., 2007. Morphodynamics of deltas under the influence of humans. Global and Planetary Change, 57(3-4), 261-282. https://doi.org/10.1016/j.gloplacha.2006.12.001 J., Vörösmarty, C., Saito, Y., Giosan, L., Nicholls, R.J., 2009. Sinking deltas due to human activities. Nature Geoscience, 2(10), 681. https://doi.org/10.1038/ngeo629

1746 Syvitski, J.P., Overeem, I., Brakenridge, G.R., Hannon, M., 2012. Floods, floodplains, delta 1747 plains — a satellite imaging approach. Sedimentary Geology, 267, 1-14.

1748 https://doi.org/10.1016/j.sedgeo.2012.05.014

1749 Tarboton, D.G., Idaszak, R., Horsburgh, J. S., Heard, J., Ames, D., Goodall, J.L., Merwade, V., 1750 Couch, A., Arrigo, J. and Hooper, R., 2014. HydroShare: advancing collaboration through 1751 hydrologic data and model sharing. 
Thanh Noi, P., Kappas, M., 2018. Comparison of random forest, k-nearest neighbor, and support vector machine classifiers for land cover classification using Sentinel-2 imagery. Sensors, 18(1), 18. https://doi.org/10.3390/s18010018

1755

1756

1757

1758

1759

1760

1761

1762

1763

1764

1765

1766

1767

1768

1769

1770

1771

1772

1773

1774

1775

1776

1777

1778

1779

1780

1781

1782

1783

1784

1785

1786

1787

1788

Theseira, M.A., Thomas, G., Taylor, J.C., Gemmell, F., Varjo, J., 2003. Sensitivity of mixture modelling to end-member selection. International Journal of Remote Sensing, 24(7), 1559-1575. https://doi.org/10.1080/01431160210146631

Tso, B., Mather, P.M., 2001. Classification Methods for Remotely Sensed Data, CRC Press.

Ulrich, M., Grosse, G., Chabrillat, S., Schirrmeister, L., 2009. Spectral characterization of periglacial surfaces and geomorphological units in the Arctic Lena Delta using field spectrometry and remote sensing. Remote Sensing of Environment, 113(6), 1220-1235. https://doi.org/10.1016/j.rse.2009.02.009

Viaña-Borja, S. P., Ortega-Sánchez, M., 2019. Automatic Methodology to Detect the Coastline from Landsat Images with a New Water Index Assessed on Three Different Spanish Mediterranean Deltas. Remote Sensing, 11(18), 2186. https://doi.org/10.3390/rs11182186

Walker, N. D., Hammack, A. B., 2000. Impacts of winter storms on circulation and sediment transport: Atchafalaya-Vermilion Bay region, Louisiana, USA. Journal of Coastal Research, 9961010.

Wang, F., Zhang, R., Zhao, H., Chen, X., 2019. Dynamic Evolution of the Yellow River Delta coastline Based on Multi-Source Remote Sensing. Ekoloji, 28(107), 615-627.

Warrender, C.E., Augusteihn, M.F., 1999. Fusion of image classification using Bayesian techniques with Markov random fields. International Journal of Remote Sensing, 20(10), 19872002. https://doi.org/10.1080/014311699212308

Wei, W., Zhang, X., Chen, X., Tang, J., Jiang, M., 2008. Wetland mapping using subpixel analysis and decision tree classification in the Yellow River delta area. ISPRS Archives, 38(B7), 667-670.

White, K., El Asmar, H.M., 1999. Monitoring changing position of coastlines using Thematic Mapper imagery, an example from the Nile Delta. Geomorphology, 29(1-2), 93-105. https://doi.org/10.1016/S0169-555X(99)00008-2

Wilson, P.A., 1997. Rule-based classification of water in Landsat MSS images using the variance filter. Photogrammetric Engineering \& Remote Sensing, 63(5), 485491.

Woodroffe, C.D., Nicholls, R.J., Saito, Y., Chen, Z., Goodbred, S.L., 2006. Landscape variability and the response of Asian megadeltas to environmental change. In: Harvey, N. (Ed.), Global Change and Integrated Coastal Management, 10, 277-314. Dordrecht, The Netherlands: Springer. https://doi.org/10.1007/1-4020-3628-0_10

Wu, C., 2009. Quantifying high-resolution impervious surfaces using spectral mixture analysis. International Journal of Remote Sensing, 30(11), 2915-2932.

https://doi.org/10.1080/01431160802558634 
Xia, L., 1998. Measurement of rapid agricultural land loss in the Pearl River Delta with the integration of remote sensing and GIS. Environment and Planning B: Planning and Design, 25(3), 447-461. https://doi.org/10.1068/b250447

Xie, Y., Sha, Z., Yu, M., 2008. Remote sensing imagery in vegetation mapping: a review. Journal of Plant Ecology, 1(1), 9-23. https://doi.org/10.1093/jpe/rtm005

Xu, H. 2006. "Modification of Normalised Difference Water Index (NDWI) to Enhance Open Water Features in Remotely Sensed Imagery." International Journal of Remote Sensing 27 (14): 3025-33. https://doi.org/10.1080/01431160600589179.

1797 Xu, J., Li, Z., Lei, L., Tian, B., Shan, Z., 2012. Land Cover Classification of Polarimetric SAR

1798 Images for the Yellow River Delta Based on Support Vector Machine. In: 2012 International 1799 Conference on Computer Vision in Remote Sensing (pp. 256-261). IEEE.

1800 https://doi.org/10.1109/CVRS.2012.6421271

1801 Yang, X., 1996. Satellite Monitoring of the Dynamic Environmental Change of the Active 1802 Yellow River Delta, China. International Archives of Photogrammetry and Remote Sensing, 31, 1803 801-806.

1804 Yang, X., Damen, M.C.J., Van Zuidam, R.A., 1999. Satellite remote sensing and GIS for the 1805 analysis of channel migration changes in the active Yellow River Delta, China. International Journal of Applied Earth Observation and Geoinformation, 1(2), 146-157. https://doi.org/10.1016/S0303-2434(99)85007-7

Yates, M.L., Cozannet, G.L., 2012. Brief communication: Evaluating European Coastal Evolution using Bayesian Networks. Natural Hazards and Earth System Sciences, 12(4), 11731177. https://doi.org/10.5194/nhess-12-1173-2012 Yeh, A.G.O., Li, X., 1997. An integrated remote sensing and GIS approach in the monitoring and evaluation of rapid urban growth for sustainable development in the Pearl River Delta, China. International Planning Studies, 2(2), 193-210. https://doi.org/10.1080/13563479708721678

1815 Yoshino, K., Kawaguchi, S., Kanda, F., Kushida, K., Tsai, F., 2014. Very high resolution plant 1816 community mapping at High Moor, Kushiro Wetland. Photogrammetric Engineering \& Remote 1817 Sensing, 80(9), 895-905. https://doi.org/10.14358/PERS.80.9.895

1818 Zhang, W., Xu, Y., Hoitink, A.J.F., Sassi, M.G., Zheng, J., Chen, X., Zhang, C., 2015. 1819 Morphological change in the Pearl River Delta, China. Marine Geology, 363, 202-219. 1820 https://doi.org/10.1016/j.margeo.2015.02.012

1821 Zhang, X., Treitz, P.M., Chen, D., Quan, C., Shi, L., Li, X., 2017. Mapping mangrove forests 1822 using multi-tidal remotely-sensed data and a decision-tree-based procedure. International Journal 1823 of Applied Earth Observation And Geoinformation, 62, 201-214.

1824 https://doi.org/10.1016/j.jag.2017.06.010 
1825 Zhang, X., Lu, Z., Jiang, S., Chi, W., Zhu, L., Wang, H., Lv, K., Wang, B., Yang, Z. (2018). The 1826 progradation and retrogradation of two newborn Huanghe (Yellow River) Delta lobes and its 1827 influencing factors. Marine Geology, 400, 38-48. https://doi.org/10.1016/j.margeo.2018.03.006

1828 Zhang, B., 2009. A CART Based Sub-pixel Method to Map Spatial and Temporal Patterns of 1829 Prairie Pothole Lakes with Climatic Variability. Unpublished manuscript, Ohio State University, 1830 Columbus, Ohio.

1831 Zhang, J., Foody, G.M., 1998. A fuzzy classification of sub-urban land cover from remotely 1832 sensed imagery. International Journal of Remote Sensing, 19(14), 2721-2738.

1833 https://doi.org/10.1080/014311698214479

1834 Zhao, B., Guo, H., Yan, Y., Wang, Q., Li, B., 2008. A simple waterline approach for tidelands 1835 using multi-temporal satellite images: a case study in the Yangtze Delta. Estuarine, Coastal and 1836 Shelf Science, 77(1), 134-142. https://doi.org/10.1016/j.ecss.2007.09.022

1837 Zhu, X., 2001. Remote sensing monitoring of coastline change in Pearl River Estuary. In: 22nd 1838 Asian Conference on Remote Sensing (Vol. 5, p. 9).

1839 Zhu, C., Zhang, X., Huang, Q., 2018. Four decades of estuarine wetland changes in the Yellow 1840 River delta based on Landsat observations between 1973 and 2013. Water, 10(7), 933.

1841 https://doi.org/10.3390/w10070933 